Panahi, H., Kobchenko, M., Meakin, P., Dysthe, D., and Renard, F. (2018) In-situ imaging of microfracture development during maturation of an organic-rich shale: effects of heating rate and confinement, Marine and Petroleum Geology, 10.1016/j.marpetgeo.2018.05.002.

\title{
In-situ imaging of fracture development during maturation of an organic-rich shale: effects of heating rate and confinement
}

Hamed Panahi ${ }^{1}$, Maya Kobchenko ${ }^{1}$, Paul Meakin ${ }^{1,3}$, Dag Kristian Dysthe ${ }^{1}$ and François Renard ${ }^{1,2}$

${ }^{1}$ Departments of Geosciences and Physics, Physics of Geological Processes, University of Oslo, Norway ${ }^{2}$ University Grenoble Alpes, CNRS, ISTerre, CS 40700, F-38058, Grenoble cedex 9, France

${ }^{3}$ Department of Physics, Temple University, Philadelphia, Pennsylvania, USA

*Corresponding author: hamedp@mail.uio.no

\begin{abstract}
The statistics and dynamics of fractures formed during the accelerated maturation of kerogen-rich shale was investigated by heating Green River Shale (R-8 unit, Piceance Basin, northwestern Colorado) core samples while 3D X-ray microtomographic images were acquired. Previous studies have shown that, when there was no confining stress, fractures formed while the kerogen contained in the shale matured, and the produced hydrocarbon was expelled through these fractures. In the present study, X-ray tomographic scans at multiple voxel sizes were conducted on similar samples during heating. In one experiment, the shale sample was tightly fitted in a non-porous ceramic tube to confine it while it was heated. Three unconfined samples were heated and then held at different final temperatures to investigate the effects of the gas production rate on fracturing. 3D image processing was used to survey fracture network development, and time-lapse 2D digital image correlation analysis was used to monitor the development of the displacement and strain fields. The results revealed that fracturing is strongly dependent on the heating rate and the final heating temperature. While most of the fractures were oriented more-or-less parallel to the bedding plane, some were strongly inclined relative to the bedding plane. The formation of inclined fractures is attributed primarily to the shape and orientation of a minority of the flake-like kerogen patches, and also to the effective stress field and fractured zones of weakness. A conceptual model is proposed to explain the dynamics of fluid expulsion and the associate fracturing behavior.
\end{abstract}


Keywords: primary migration, kerogen, shale, fracture, X-ray microtomography, digital image correlation

\section{Highlights}

- 4D X-ray tomography of confined and unconfined shale samples show microfracturing during heating

- 2D digital image correlation analyses reveal sub-micrometer size microfractures

- Formation of microfractures strongly inclined relative to bedding plane and the sub-horizontal ones

- A conceptual model of fracture initiation, propagation, closure and reopening during primary migration

\section{INTRODUCTION}

\subsection{Mechanisms of primary migration}

It has been proposed that the transport of fluids through fracture and pore networks formed during catagenesis of organic rich rocks plays a critically important role in primary migration [Kalani et al., 2015]. However, the process of primary migration is still not well understood, and other transport mechanisms have been proposed, including: migration through a continuous oil saturated kerogen network [McAuliffe, 1979], migration of micro-droplets, migration of micelles [Cordell, 1973], migration of oil emulsion, migration of oil dissolved in water [Bray \& Foster, 1980], and migration of oil dissolved in gas [Price, 1989]. The effect of these mechanisms may vary, but they are believed to be insignificant in comparison with hydrocarbon transport through fractures, especially over large distances [Snarskiy, 1961; Tissot \& Welte, 1978; England et al., 1987; Hunt, 1990; Lafargue et al., 1994; Rudkiewicz et al., 1994; Lafargue et al., 1998; Ougier-Simonin et al., 2016]. Previous studies support the idea that fractures play an important role in primary migration because they can pervade mature source rocks [Chanchani et al., 1996; Lash \& Engelder, 2005; Kalani et al., 2015]. Moreover, organic rich specimens that have been thermally decomposed under confinement in the laboratory, or natural samples studied by microstructural analyses [Kalani et al., 2015], have revealed fractures filled with mobile organic matter. Laboratory experiments also suggested that kerogen transformation leads to the formation of fractures whose propagation direction (predominantly sub-parallel to the bedding plane) are controlled by the anisotropic stress and rock mechanical properties (strength and toughness), and by the orientation of kerogen patches in the source rock [Vernik, 1994; Kobchenko et al., 2011; Glatz et al., 2016]. In comparison with a previous study [Panahi et al, 2012], the rate of temperature increase, before the sample was held at a constant temperature, was slower. By increasing the image resolution by a factor of about ten, considerably smaller fractures could be detected and studied in the work reported here. 
Most experimental studies of shale maturation were carried out on unconfined samples, which exaggerate the influence of fractures in increasing porosity and permeability [Burnham, 2017]. It is therefore important to investigate the formation of fractures associated with hydrocarbon formation and their contribution to the development of porosity and permeability under more realistic conditions. Moreover, the rate of heating of the samples during maturation is also expected to play an important role [Dutrow and Norton, 1995].

\subsection{Characterization of microfractures in shales}

Previous in situ X-ray microtomography experiments on shales have demonstrated that many fractures nucleate and grow along lamination planes [Kobchenko et al., 2011; Panahi et al., 2012; Saif et al., 2016; Saif et al., 2017; Figueroa Pilz et al., 2017]. Since lamination planes are usually oriented more-or-less horizontally, and the direction of greatest principle compressive stress is usually sub-vertical at depths of $\approx 1$ km or greater [Brown \& Hoek, 1978; McGarr \& Gay, 1978; Savage et al., 1992; Plumb, 1994; Zang \& Stephansson, 2009], the direction of greatest compressive stress is typically perpendicular to the lamination plane during natural catagenesis. Jin et al. [2010] proposed a model for rock fracture coupled with kerogen to oil transformation kinetics, which indicates that the duration of crack propagation and oil pressure on the fracture plane strongly depends on temperature. Goulart Teixeira et al. [2017] proposed a discrete element model that showed that the formation of three-dimensional percolating fracture networks depends on the state of differential stress and initial kerogen distribution. A larger compressive stress in the direction perpendicular to the horizontal bedding plane favors vertical fracture growth while anisotropy associated with bedding favors horizontal fracture growth. Kalani et al. [2015] showed that most kerogen patches are aligned parallel to the bedding plane, but some are oriented in other directions. Saif et al. [2016; 2017] studied the microstructure of immature Green River Shale under vacuum pyrolysis conditions using X-ray tomography at $12 \mu \mathrm{m}$ and $2 \mu \mathrm{m}$ voxel sizes and detected the formation of large (relative to the characteristic size of pre-existing pores) micro-voids at around $390^{\circ} \mathrm{C}$, which further increased in size when the temperature was increased to $500^{\circ} \mathrm{C}$. These large strongly anisometric voids were interpreted as fractures that were oriented more-or-less parallel to the bedding plane, and formed a fracture network along the bedding plane. Figueroa Pilz et al. [2017] used X-ray tomography to measure 3D displacement fields using digital volume correlation (DVC) analysis on unconfined UK Kimmeridge Clay samples while they were heated from $20^{\circ} \mathrm{C}$ to $400^{\circ} \mathrm{C}$. They concluded that the main driver for fracturing is opening displacement perpendicular to the bedding plane. Burnham [2017] analyzed the effect of confinement on the change in porosity and permeability that occurred during the retorting of Green River Shale. He showed that several empirical permeability-porosity relationships are equally consistent with experimental and field data, and that the increase in permeability during retorting was reduced by up to three orders of magnitude when the sample was confined. His study was based on data obtained by Thomas [1966] and data from inside and 
outside in-situ retorts in the R0 and R0-L0 zones of the Garden Gulch member of the Green River Formation obtained by Kibodeaux [2014] during a field experiment. Thomas [1966] conducted experiments in which core samples were immersed in a bed of glass microspheres inside a cylinder and a piston was used to exert a pressure on the upper surface of the bed. Assuming that the packing of microspheres acted like a fluid, Thomas concluded that the shale was subjected to an isotropic stress (pressure) of 0.7 to $17 \mathrm{MPa}$, until the glass beads became contaminated with coke, and no longer acted as a fluid. Peng \& Xiao [2017] studied the complex two-phase flow of oil and water in Upper Cretaceous Eagle Ford Shale and Mississippian Barnett Shale samples using X-ray tomography and questioned the validity of Darcy permeabilities and wettabilities calculated from X-ray tomograms when the nano to microscale pore structure is simplified.

In the present study, a pre-existing workflow for processing tight rock tomograms, acquired under in situ conditions [Kobchenko et al., 2011; Panahi et al., 2012], was further refined. The objective was to reduce the data processing time and thus handle higher resolution images to investigate fracture propagation under confinement. The higher resolution made it possible to investigate an earlier stage of thermal maturation during which fractures are smaller and more difficult to detect and characterize than in later stages. Analysis of the statistics of segmented fractures (number, density, volume, surface area and porosity) was also used to quantitatively compare fracturing under different experimental conditions and at different times during each experiment. Two-dimensional planar digital image correlation (DIC) analysis [Hild \& Roux, 2006; Pan et al., 2009] was used to characterize the changes in the displacement field and strain field between successive 3D scans. Furthermore, by applying DIC analysis on horizontal slices (bedding parallel) and vertical cross-sections (bedding perpendicular) the effects of shale anisotropy on strain during accelerated kerogen maturation were studied. This showed that fractures with orientations that deviated significantly from the horizontal (bedding) plane, as well as sub-horizontal fractures, contributed to the 3D network of fractures. The formation of deviated fractures was attributed to the orientation distribution and complex shapes of kerogen flakes and nearby zones of weakness or pores. Complex fracture propagation/opening and closing dynamics which was observed in all experiments was physically explained. In the work reported here, we observed that the heating schedule directly affects the fracture geometry/statistics.

\section{MATERIALS AND METHODS}

In situ dynamic X-ray computed tomography images were used to detect the nucleation and measure the growth of fractures in immature Green River Shale samples while they were heated, both in confined and unconfined conditions, to accelerate kerogen maturation. Experiments were conducted with either no confinement but with different heating rates up to final temperatures of $390^{\circ} \mathrm{C}, 335^{\circ} \mathrm{C}$ and $290^{\circ} \mathrm{C}$ for experiments 1-3 respectively or with confinement but heating at a constant rate to a much higher temperature of $750^{\circ} \mathrm{C}$ (Table 1). Core samples were extracted from a block of shale perpendicular to the 
bedding plane, which was part of a large core sampled from an outcrop of the organic-rich R-8 unit of the Green River Shale Formation, Piceance Basin, northwestern Colorado. The shale had a total organic content of approximately $10 \%$, consisting mainly of immature type I kerogen (high $\mathrm{H} / \mathrm{C}$ kerogen formed primarily from lacustrine biomass). The same block was used and characterized in previous studies [Kobchenko et al., 2011; Panahi et al., 2012]. The samples were imaged using synchrotron computed X-ray microtomography to investigate geometrically complex fractures and their growth inside the material. Each sample was scanned first with a voxel size of 3.5 or 2.8 microns. Then a volume in the central part of the sample was scanned at a higher resolution with a voxel size that was five times smaller ( 0.7 or 0.56 micron).

\subsection{Sample preparation and experimental setup}

The sample dimensions and experimental conditions are given in Table 1. Samples were not confined for experiments 1 to 3 . In these experiments the samples were first heated to different temperatures $(290,335$ and $390^{\circ} \mathrm{C}$ ) during a period of 10 minutes, and then they were held at those temperatures for 78 to 110 minutes. A ceramic tube with an inner diameter of $2 \mathrm{~mm}$ was used to confine the rock sample of experiment 4 as it was heated from 26 to $750^{\circ} \mathrm{C}$ at a quasi-constant rate of $1.4^{\circ} \mathrm{C}$ per minute. The $1 \mathrm{~cm}$ long shale core sample had nominally the same diameter as the inner diameter of the ceramic tube. It was placed inside the tube, and two cylindrical steel plugs were cemented to the inside of the tube, in contact with the flat ends of the sample, using a temperature-resistant ceramic cement, Cerastil - $\mathrm{C} 5$, to confine the samples. The ceramic tube was non-porous and it was assumed that the produced fluids were retained with the sample in the closed cylinder. Examination of the tube after the experiment gave no indication of cracking or leakage such as staining of the exterior of the tube. A confining stress was imposed on the sample of experiment 4 during heating because the thermal expansion coefficient of the shale is larger than that of the ceramic and because of the volume increase accompanying the maturation of kerogen and decomposition of inorganic minerals into new solid phases and fluids. However, the exact value of the confining stress could not be measured.

A maximum confining stress of $66 \mathrm{MPa}$ during experiment 4 was estimated from the tensile strength of the ceramic using Lamé's equations for thick-walled tubes composed of a brittle material [Timoshenko et al., 1956], which are applicable only far from the steel plugs in the ends of the ceramic cylinder. The coefficient of thermal expansion of an unconfined sample prepared from the same block of shale was determined in a previous study [Kobchenko et al., 2011; Panahi et al., 2012] and found to be equal to $55 \times 10^{-6} /{ }^{\circ} \mathrm{C}$ in the vertical direction, perpendicular to the bedding plane, and $25 \times 10^{-6} /{ }^{\circ} \mathrm{C}$ in the horizontal direction, parallel to bedding over the temperature range of $100-400^{\circ} \mathrm{C}$. For mullite and steel, the coefficients of thermal expansion are $\approx 5.5 \times 10^{-6} /{ }^{\circ} \mathrm{C}$ and $\approx 11 \times 10^{-6} /{ }^{\circ} \mathrm{C}$, respectively. Mullite has a relatively low tensile strength $(110$ $\mathrm{MPa}$ ) and high stiffness. In experiment 4 (the only experiment with confinement), the maximum confining 
compressive stress was probably below the internal pressure of $66 \mathrm{MPa}$ required to fracture a brittle ceramic tube with a tensile strength of $110 \mathrm{MPa}$ and the dimensions of tube used in this experiment, since the tube did not fracture. However, there is significant uncertainty in this estimate of the maximum confining stress because of sample to sample variation in the strengths of mullite tubes, the finite ratio between the length and diameter of the tube and the stress associated with the expansion of the steel plugs and cement. There is also substantial uncertainty in the confinement stress during the experiments because the thermal expansion coefficients of the shale were measured under unconfined conditions that enable expulsion of fluids and reduce the stress induced closure of fractures and pores, and because intensely fractured materials such as shales with a high content of kerogen undergoing catagenesis cannot be assumed to behave as linear elastic materials with elastic moduli that are independent of the time-temperature history [Nygård et al., 2006; Chen et al., 2014; Guo et al., 2015].

For all experiments, the sample assembly was attached to a ceramic rod, which was used to mount the sample in an infrared custom-made oven, where it was exposed to the X-ray beam. The programmable oven was used to control the heating ramp and maximum temperature, as well as the duration of the experiment. The X-ray microtomography imaging was carried out using beamline ID19 at the European Synchrotron Radiation Facility (ESRF). A series of 1,500-3,000 2D radiographs were recorded while the sample was rotated by $180^{\circ}$ around a beam-perpendicular axis, aligned with the axis of the ceramic rod. The beam energy for these experiments was $31 \mathrm{keV}$. The experiments were conducted under air at atmospheric pressure. The resolution of the X-ray tomograms was sensitive to the acquisition time which was set to 6.95 $\mathrm{min} / \mathrm{scan}$. There was a trade-off between faster image acquisition time and resolution both of which affected detection of the temperature at which fractures were first detected.

\subsection{Data processing of the $3 D$ tomography volumes to isolate fractures}

Processing of the 3D tomography volumes was performed using the commercial software AvizoFire, with the objective of identifying and measuring the fractures that developed as the temperature was increased, and studying their evolution over time (see Supplementary Material). A number of metrics were used to quantitatively track fracture network evolution: 1) The fracture number density, defined as the number of voids consisting of more than 1,000 voxels, per unit volume, with units of $\mathrm{L}^{-3} ; 2$ ) the fracture intensity, defined as the fracture surface area per unit volume, with units of $\left.\mathrm{L}^{-1} ; 3\right)$ the average distance between fractures is defined as the average of the distances along each vertical column of voxels that spans the gap between one fracture and another without intersecting another fracture and 4) the total X-ray tomography porosity defined as the ratio between the volume of all fractures and pores that could be resolved using Xray computed tomography and the total volume of the region from which X-ray attenuation data was acquired and analyzed. Here, a void is defined as a set of voxels filled with low X-ray attenuation material 
in which every voxel can be reached from every other voxel by a path consisting of steps between nearest neighbor voxels that are also filled with low X-ray attenuation material. Also, 2D digital image correlation analysis (see Supplementary Material) was used to track the displacement fields as the shale samples and the kerogen that they contained were thermally altered, and the strain fields were calculated from the displacement fields. This made it possible to relate the strain of the samples with the spatial evolution of the fractures within them.

\section{RESULTS}

\subsection{Fracture development in the unconfined experiment}

Here, and in the following sections, porosity refers to the X-ray tomography porosity. Fractures were detected in all experiments (see Table 1 for experimental conditions). They appeared more continuous in the higher resolution images than in those from a previous study carried out at lower resolution and a slightly higher temperature $\left(400^{\circ} \mathrm{C}\right)$ [Panahi et al., 2012]. In experiment 1 (unconfined) fractures formed below $390^{\circ} \mathrm{C}$, and some of them closed after that temperature was reached (Figure 1). We compared fracture number density and fracture intensity for scans 2 and 5 of experiment 1 . For experiment 1 , the fractures (voids with connected volume above 1,000 voxels) were selected in the second scan (acquired between 15.6 and $31.2 \mathrm{~min}$. at a constant temperature of $390^{\circ} \mathrm{C}$, after completion of the initial $10 \mathrm{~min}$. heating from room temperature to $390^{\circ} \mathrm{C}$ ) and the fifth scan (acquired between 62.8-78 min at a constant temperature of $390^{\circ} \mathrm{C}$ ). The fracture number density was slightly larger for the second scan than for the fifth scan. The fracture intensity was three orders of magnitude larger for the second scan than for the fifth scan. The fractures appeared far more continuous, and their shapes were more complex in scan 2 (the first stage after temperature stabilization) than in scan 5 (during the post heating stage), and the average fracture surface area and average fracture volume were two orders of magnitude larger for scan 2 than for scan 5- see Table 2. Also, experiment 2 at a higher final temperature $\left(335^{\circ} \mathrm{C}\right.$ versus $\left.290^{\circ} \mathrm{C}\right)$ displayed 3.1 times as many voids with volumes above 1,000 voxels as experiment 3 , and the fracture intensity was 2.3 times higher (Table 2).

To summarize, comparing the fracture networks of experiments 1,2 and 3 , with unconfined samples, at their final heating temperatures $\left(390^{\circ} \mathrm{C}, 335^{\circ} \mathrm{C}\right.$ and $\left.290^{\circ} \mathrm{C}\right)$ it was observed that the higher the final temperature, the higher the fracture number density became (Figure 2-a to 2-c). The average distance between fractures decreased as the final heating temperature was increased (Figure 2-d). The final fracture porosity and the final fracture intensity also increased as the final heating temperature increased (Table 2).

\subsection{Fracture development in the confined experiment}


During experiment 4, a 2-mm diameter shale sample, confined inside a ceramic tube, was imaged while it was subjected to a heating ramp from $26^{\circ} \mathrm{C}$ to $750^{\circ} \mathrm{C}$. The field of view of the detector covered part of the sample in the center in which voids could be detected. The evolution of the total generated porosity (consisting of voids with volumes $>1,000$ voxels, defined as fractures, plus voids with volumes $\leq 1,000$ voxels, defined as pores) was analyzed. Connected voids are identified as voids for which a voxel in one void is the next-nearest neighbor to a voxel in the other void. The changes in connectivity between voids due to the increase in temperature and time were monitored at a resolution of 0.7 micron. However, only trends in connectivity could be established since the imaged area covered only a part of the sample and other definitions of connectivity could have been used. In addition, some fractures may have been connected to other fractures outside of the imaged volume.

The total X-ray tomography porosity increased as the temperature was increased, and decreased as the temperature was decreased after the maximum temperature of $750^{\circ} \mathrm{C}$ had been reached (Figure 3). Initially, the total porosity increased due to the appearance of the large fractured volume inside the field of view. Organic rich Green River Shale has a low porosity and pores with characteristic dimensions that are too small to be detected by X-ray tomography, even at the highest resolution of 0.56 micron used in this investigation, may account for most of the pore volume [Burnham, 2017; Ezidiegwu, 2015]. Even after in situ retorting, most of the porosity may reside in pores with "diameters" less than 0.5 micron [Burnham, 2017].

\subsection{Evolution of the number of fractures with time}

To better monitor fracture opening and closing, the number and volume of fractures and pores and their respective porosities were measured. The blue curve in Figure 3a shows the change in the total porosity (the volume fraction of voids), with temperature. The green curve in figure $3 \mathrm{a}$ shows how the volume fraction of the voids with volumes $>1,000$ voxels (i.e. fracture porosity) changes with temperature. This indicates a sequence of fracture closing and reopening or fracture closing and new fracture formation processes. The black curve in figure $3 \mathrm{a}$ shows the contribution of the pores distributed throughout the sample to the total porosity. At the X-ray tomography resolution of this experiment, these pores, with volumes $<1,000$ voxels, are not part of a pore/fracture network, and they are denoted in the figure by "isolated porosity". Since much or most of the pore volume may reside in nanoscale pores, nanoscale pore networks (that cannot be detected) may connect the pores that were detected and characterized using X-ray tomography with other pores and fractures. However, these pore networks can be expected to have very low permeabilities, and depending on wetting behaviors, they may also have very high capillary entry pressures. Consequently, characterizing voids with volumes $<1,000$ voxels as isolated pores is reasonable from an operational point of view. This matrix porosity was calculated by subtracting the fracture porosity 
from the total porosity. Figure $3 \mathrm{~b}$ shows how the number of pores changed during experiment 4 with confinement.

\subsection{Digital Image Correlation analyses}

The displacement and strain fields for slices parallel to the bedding plane were calculated using 2D DIC analtyis for experiments 2, 3 (unconfined) and experiment 4 (confined), see Supplementary Material. For experiment 4 , the displacements, $\mathrm{u}(\mathrm{x}, \mathrm{y})$ and $\mathrm{v}(\mathrm{x}, \mathrm{y})$ in the bedding-parallel, $(\mathrm{x}, \mathrm{y})$ plane, where $\mathrm{u}$ is the displacement in the $\mathrm{x}$ direction and $\mathrm{v}$ is the displacement in the $\mathrm{y}$ direction were calculated. As the temperature was changed from $\approx 308^{\circ} \mathrm{C}$ to $\approx 319^{\circ} \mathrm{C}, 2 \mathrm{D}$ DIC analysis indicated that the strain within this plane produced by heating was anisotropic (Figure 4). As the boundaries of the sample were approached, the strain became even more anisotropic and the displacements decreased. These effects are attributed to friction and normal stress at the interface between the shale and the confining ceramic tube. Although the tube expanded as the temperature and pressure/compressive stress increased, the very low thermal expansion coefficient and very high stiffness of the ceramic, resulted in confinement of the sample.

The mean coherence (also called spectral coherence or magnitude-squared coherence) is the ratio between the $\mathrm{u}(\mathrm{x}, \mathrm{y})$ and $\mathrm{v}(\mathrm{x}, \mathrm{y})$ displacements[Bendat \& Piersol, 1986; White \& Boashash, 1990]. The coherence between the $\mathrm{u}$ displacement averaged over $\mathrm{y}$ axis plotted in the $\mathrm{x}$ direction and the $\mathrm{v}$ displacement averaged over $\mathrm{x}$ axis plotted in the $\mathrm{y}$ direction was close to 0.61 for a slice parallel to the bedding plane for experiment 4 (for arbitrarily chosen $\mathrm{x}$ and $\mathrm{y}$ coordinates). The $\mathrm{u}$ displacement averaged over the $\mathrm{x}$ direction plotted in the $\mathrm{y}$ direction and the $\mathrm{v}$ displacement averaged over the $\mathrm{y}$ direction plotted in the $\mathrm{x}$ direction along the same plane had a mean coherence of 0.47 . The similarity in shapes but difference in magnitudes (characterized by the mean coherence that is substantially less than unity) between the $u$ and $v$ displacement profiles shown in figure $4 \mathrm{a}$ and figure $4 \mathrm{~b}$ indicate that the displacement field in the horizontal plane was significantly anisotropic.

The in-plane displacement fields, $\mathrm{u}(\mathrm{x}, \mathrm{y})$ and $\mathrm{v}(\mathrm{x}, \mathrm{y})$, and the total displacement field $-\left[\mathrm{u}(\mathrm{x}, \mathrm{y})^{2}+\mathrm{v}(\mathrm{x}, \mathrm{y})^{2}\right]^{1 / 2}$ - with respect to the reference image (the first image after the constant temperature of $290^{\circ} \mathrm{C}$ had been reached) in a common bedding-parallel slice of the three sequential images of experiment 3 with an unconfined sample are compared in Figure 5. Both positive displacements (warm colors) and negative displacements (cold colors) were observed. Color changes indicate translation, color gradients indicate strain and color discontinuities indicate the intersections of fractures with the selected bedding-parallel plane.

The Lagrangian shear strain field ( $E_{x y}$, see Supplementary Material) calculated from the displacement field for an unconfined shale cylinder heated to $290^{\circ} \mathrm{C}$ (Experiment 3) is shown in Figure 6. The Lagrangian 
normal strain fields were also calculated. Although the horizontal Cartesian coordinate system chosen is arbitrary, the strain field in any other horizontal coordinate system can be obtained from it by matrix transformation. $\mathrm{E}_{\mathrm{xy}}$ was calculated from the displacement data of Figure 5 and shows the cumulative strain fields relative to the reference image, obtained immediately after the sample had been heated to $290^{\circ} \mathrm{C}$, (first row in Figure 6) and also the changes in the strain field from one data acquisition stage to the next (second row in Figure 6). Strain discontinuities are interpreted as intersections between the selected horizontal bedding-parallel slice and fractures. Some of these fractures do not have a visible aperture and they can be identified only by DIC analysis of time lapse volumes. The fracture fronts that correspond to strain discontinuities, are clearly visible in the shear strain maps and show large variability at different stages of heating. Because large fractures formed by the coalescence of smaller fractures in heterogeneous materials may have very complex three-dimensional shapes, the intersection between a single fracture and a planar cut cannot be distinguished from the intersection between a planar cut and two or more fractures or the intersection between a planar cut and several fractures and other voids, without examination of a stack of closely spaced parallel cuts.

The changes in the fracture patterns indicate that fractures opened (and possibly grew) and closed (became detectable and undetectable by DIC analysis). The average strain decreased from the first stage to the second stage and then increased from the second stage to the third as the fractures closed and reopened, and the shear tensor component $E_{\mathrm{xz}}$ on Figure 9-b confirms this observation while there appears to be little or no change in $E_{x x}$.

The displacement and strain fields were also calculated for experiment 2 (heated to $335^{\circ} \mathrm{C}$ instead of $290^{\circ} \mathrm{C}$ in experiment 3, both unconfined). Three successive cumulative displacement and strain fields were calculated (The three images were recorded over the time intervals $60-80 \mathrm{~min}, 80-100 \mathrm{~min}$ and 100-120 $\min )$. The $E_{x x}, E_{x y}$ and $E_{y y}$ components of the $2 D$ strain tensor are shown in Figure 7. Compared to experiment 3 (Figure 6), the fractures appeared to be more connected in the higher temperature experiment.

The evolution over time of fractures that intersect selected vertical cross-sections (cross-sections perpendicular to the bedding plane and parallel to the axis of the cylindrical samples) was analyzed and the displacement fields in these cross-sections was studied. Two orthogonal bedding-perpendicular crosssections were selected (Figure 8-a and 8-b). There was some displacement perpendicular to these two vertical planes, which could reduce the reliability and accuracy of the DIC analysis conducted to determine the in-plane displacements. However, these perpendicular displacements were insignificant except where horizontal fractures intersected the vertical planes. The evolution of the fractures in the $\mathrm{x}-\mathrm{z}$ plane as the sample was heated (for cross-section 1) is shown at three stages in Figure 8-c. There were diagonal, nonhorizontal or geometrically complex fractures which were difficult to detect and characterize. The $u$ and $\mathrm{w}$ 
displacement fields were calculated for the chosen vertical cross-section (Figure 8-d). Several nonhorizontal fractures that could not be identified directly in the X-ray tomography scans could be clearly identified by the DIC analysis, and they can be clearly seen in the displacement and strain fields. In each vertical cross-section perpendicular to the bedding plane, the perpendicular (vertical) and parallel (horizontal) displacement fields were very similar and the displacement maps represented by the color maps in Figure 8-d are quite similar. Figure 8-d indicates that the displacement fields perpendicular and parallel to the bedding plane in the vertical planes were heterogeneous but not strongly anisotropic.

The u-displacement averaged in the $\mathrm{x}$-direction and the $\mathrm{w}$-displacement averaged in the $\mathrm{z}$-direction for the orthogonal vertical cross-sections 1 and 2 are more-or-less linear functions of $\mathrm{x}$ and $\mathrm{z}$ respectively (Figure 9-a) but show different slopes. The slopes of the straight lines fitted to the displacements indicate that the gradient of the displacement is substantially larger in the $\mathrm{z}$ direction than in the $\mathrm{x}$ direction, and therefore the deformation that occurs during heating is anisotropic. Linear changes in displacements also indicate that the heating driven expansion was essentially homogeneous in both directions during this experiment as was the thermal expansion of Green River Shale investigated in a previous study under unconfined conditions [Panahi et al., 2012].

The three components of the strain field in the $(\mathrm{x}, \mathrm{z})$ plane were calculated (two normal strains and one shear strain) (See equations 3 to 5 in the Supplementary Material) for cross section 2 of Figure 8, where $E_{\mathrm{xx}}$ and $\mathrm{E}_{\mathrm{xz}}$ are shown. Fractures that are inclined relative to the bedding plane can be observed as discontinuities in the strain fields. There is a strong overlap between the discontinuities identified as fractures (intersections of fractures with the chosen vertical cross section) in all three strain fields. However, it appears that some fractures developed more by shear failure than by opening mode failure (Figure 9-b).

\section{DISCUSSION}

In an earlier investigation, a time-lapse sequence of 3D X-ray computed tomography images was acquired and used to study fracture network evolution under unconfined conditions in a shale sample from the same large Green River Shale core specimen [Kobchenko et al., 2011; Panahi et al., 2012]. Such experiments were carried out under similar conditions to those used in experiment 1 , but with a slower rate of temperature increase before the sample was held at a constant temperature of $400^{\circ} \mathrm{C}$. By increasing the image resolution by a factor of about ten, considerably smaller fractures could be detected and studied in the work reported here. The 3D image analysis workflow, which was developed earlier to extract very small fracture apertures from 3D X-ray computed tomography images of tight-rock samples [Panahi et al., 2012], was further optimized by adding filtering steps (Supplementary Material Figures S1 and S2), which resulted in less processing time and a higher number of microfractures detected. 
DIC analysis enabled the strain fronts in bed-parallel slices and bed-perpendicular cross-sections of the samples to be detected. The use of higher resolution images and application of a more thorough 2D DIC analysis made it possible to detect both horizontal and non-horizontal fractures that were formed in the experiments. The geometrically complex displacement discontinuities, interpreted as fractures, are consistent with the fractures that can be observed directly in the 3D tomographic volumes. 2D DIC analysis resolves sub-pixel scale displacements and it has a higher spatial resolution than direct 3D image analysis. In practice, 2D DIC analysis enabled both bedding-parallel fractures and fractures with orientations that deviate strongly from the bedding plane to be detected. It was possible to detect some of the deviated fractures in the new high resolution 3D images, but with great difficulty. In one cross section, it was possible to detect several fractures that were significantly deviated from the bedding plane.

\subsection{Evolution of the fracture network with temperature changes}

The higher spatial resolution in the present study, relative to earlier experiments [Kobchenko et al., 2011; Panahi et al., 2012], revealed a much higher fracture density, intensity, porosity, connectivity, and continuity. However, because of different acquisition parameters, variations in the X-ray beam characteristics and heating schedule, the results obtained during the present experimental campaign and the previous campaigns cannot be quantitatively compared. The final temperature is one of the conditions that control fracture propagation in the experiments without confinement. Through observations and statistical analysis it was found that the higher the final temperature the higher the average fracture surface area, average fracture volume, fracture intensity, fracture density and final fracture porosity for the same experiment duration (Figure 2d and Table 2; for experimental conditions refer to Table 1). During natural catagenesis, the average molecular mass of the hydrocarbon produced decreases as the temperature and pressure increase very slowly, and high molecular mass hydrocarbons are cracked. The rates of most of the individual reactions in the extremely complex network of reactions that control catagenesis increase rapidly with increasing temperature, and the relative rates of activation-controlled reactions change as the temperature increases. Consequently, at the temperatures used in the experiments reported here, the rate of catagenesis is higher and the composition of the fluid produced by catagenesis is different compared with catagenesis under most natural conditions. However, the intrusion of magma, in the form of dikes and/or sills, into sedimentary basins can drive rapid catagenesis under conditions that may be similar to those in experiment 4 under confined conditions, and rapid maturation under confined conditions also occurs during the in situ retorting of oil shale [Simoneit, 1988; Dutkiewicz et al., 2004; Zhu et al., 2007].

Providing the initial heating rate is fast enough, the rate of fluid production at a constant temperature will be higher if the temperature is higher. A higher volume of fluid will be produced at a higher rate until catagenesis approaches completion, particularly under unconfined conditions for which the specific 
volumes of the gas phase is large. The substantial changes in the fracture patterns from the second image to the third (last) in the unconfined experiments (experiments 1-3) and the maintained fluid production throughout the constant temperature stage indicates that catagenesis was not completed during these experiments (i.e., the kerogen was not completely converted to char and fluids). The conclusion that catagenesis was not complete in these experiments at temperatures of $290-390{ }^{\circ} \mathrm{C}$ is supported by the sudden increase in porosity (both total and fracture X-ray tomography porosities) observed from $500^{\circ} \mathrm{C}$ to $650^{\circ} \mathrm{C}$ during experiment 4 (Figure 3a) under confined conditions. At temperatures below $200^{\circ} \mathrm{C}$, fracturing during the experiments reported here can be attributed to water vapor produced by desorption, and by the decomposition of sodium bicarbonate (nahcolite), sodium sesquicarbonatedihydrate (trona) and other evaporate minerals which are often abundant in Green River Shale [Beard \& Van Meurs, 1973; Ruble et al., 2001]. At higher temperatures, fracturing is driven primarily by organic matter maturation and decomposition of inorganic matter. Dehydration of illite (less than 5 wt. \% in immature Green River Shale samples [Saif et al., 2017]) at 340-360 ${ }^{\circ} \mathrm{C}$ and decomposition of dawsonite, analcime and other minerals may also contribute to fracturing in the $200-400{ }^{\circ} \mathrm{C}$ range [Smith \& Milton, 1966; Beard et al., 1974; McKay \& Chong, 1983, Le Doan et al., 2013]. Expansion and vaporization of free water and other fluids may also play a role in fracture nucleation and propagation. These fluid producing processes, and the thermal expansion of fluids, will also increase the confining stress [Chenevert, 1970; Hueckel \& Borsetto, 1990; Bustin et al., 2008]. $\mathrm{Mg}, \mathrm{Ca}$ and $\mathrm{Ba}$ carbonates are not expected to decompose significantly at the highest temperatures used in the experiments reported here if the $\mathrm{CO}_{2}$ partial pressure is on the order of $0.1 \mathrm{MPa}$ (on the order of one atmosphere) or greater. While the maturation of kerogen is almost certainly the dominant fluid producing process at temperatures of $290-750{ }^{\circ} \mathrm{C}$ (the focus of the experiments reported here), the expansion and phase transition of fluids produced during heating at lower temperatures may play a significant role at temperatures $\geq 290{ }^{\circ} \mathrm{C}$, because of the high immature kerogen content of the Green River Shale [Le Doan et al., 2013; Burnham \& McKonaghi, 2014; Jagniecki \& Lowenstein, 2015].

\subsection{Dependence of the fracture network on the confining pressure}

If the sample is completely confined, the strain that develops during an experiment will be controlled in large part by the ceramic, which has higher elastic moduli than the shale. If there is a small gap between the shale and the ceramic, then the shale will expand freely until a confining stress develops because of the contact between the shale and the ceramic tube. As the sample expands, all or part of some of the fractures may move out of the field of view, and anisotropic deformation may move all or part of some of the fractures into or out of the field of view, thus contributing to the change in X-ray tomography porosity. The porosity increased as the shale was heated from $50^{\circ} \mathrm{C}$ to $\approx 250^{\circ} \mathrm{C}$, followed by a more or less constant porosity between $\approx 250^{\circ} \mathrm{C}$ and $\approx 700^{\circ} \mathrm{C}$ (Figure 3a). This suggests that the sample may have expanded more-or-less 
freely until a temperature of $\approx 250^{\circ} \mathrm{C}$ was reached, and that confinement prevented further increase in porosity between $\approx 250^{\circ} \mathrm{C}$ and $\approx 700^{\circ} \mathrm{C}$. The displacements shown in Figure 4 also suggest that in the $\approx 308^{\circ} \mathrm{C}$ to $\approx 319^{\circ} \mathrm{C}$ temperature range, normal and tangential stress at the interface between the shale and the ceramic tube had an important effect on the thermally driven deformation of the sample.

As expected, heating an unconfined shale sample (experiments 1,2 and 3) resulted in the formation of more fractures than heating the confined shale sample (experiment 4) because confinement (compressive stress and/or fluid pressure) reduced the fluid volume and inhibited fracturing, even though the Green River Shale sample was heated to a much higher temperature and for a longer time during experiment 4 . However, because of the uncertainty in the confinement stress and the differences in the temperature-time history, it is not possible to reach quantitative conclusions. Although pressure suppresses kerogen maturation, the maximum confining stress of $\leq 66 \mathrm{MPa}$ in experiment 4 was much too small to significantly inhibit the production of hydrocarbons under the time/temperature conditions of this experiment or prevent the almost complete conversion of kerogen into low molecular mass hydrocarbons and high carbon char on longer time scales.

Increased fluid pressure reduces the effective compressive stresses that act on rocks at depth and produce tensile fractures [Engelder \& Lacazette, 1990; English, 2012]. The tensile fractures formed sub-parallel to the lamination surfaces are larger than those that grow in other directions. This is in agreement with the hypotheses that kerogen flakes, which act as pre-existing fractures as fluids (primarily oil, gas, $\mathrm{CO}_{2}$ and $\mathrm{H}_{2} \mathrm{O}$ ) are produced from the kerogen, are preferentially aligned with the bedding plane, and that the stress concentration at the perimeters of the pre-existing fractures favors continued fracture propagation along the bedding plane. This facilitates the merging of fractures formed from kerogen flakes that lie within the same lamination. Anisotropic material properties and anisotropic stress probably play secondary roles. At shallow depths (less than about $1 \mathrm{~km}$ ) the smallest principal compressive stress is most often the lithostatic stress, and horizontal fracturing is favored. At greater depths, the smallest principal compressive stress is usually in the horizontal plane, [Brown \& Hoek, 1978; McGarr \& Gay, 1978; Plumb, 1994; Savage et al, 1992; Zang, A. and Stephansson, 2009] and vertical fracturing is favored [Engelder \& Lacazette, 1990; Vernik, 1994; English, 2012; Goulart Teixeira et al., 2017]. The stress anisotropy, complex shapes and out-of-plane orientations of some of the kerogen particles, cause out-of-plane fracture propagation, which contributes to migration along directions other than horizontal. In our experiments, fractures propagated both sub-parallel and significantly inclined relative to the bedding plane, though fractures sub-parallel to the bedding plane were far more abundant.

\subsection{Dynamics of fluid expulsion and associate fracturing behavior}


In experiments 1-3, after a constant temperature was reached, most of the fractures formed during the early stages of heating, and during the rest of the experiment many of the fractures that formed earlier closed as the fluid they contained escaped because there was no confinement. Some of these fractures may reopen later as new fluid is generated near them and the local fluid pressure increases as evidenced by the reduction and then increase in areas of the fracture apertures in the plane of the slices for three consecutive slices of experiment 3. In experiment 4, under confined conditions, the fracture porosity fluctuated as the temperature increased, with a weak upward trend. This behavior is similar to that observed in model systems where fluid is produced internally in an elastic solid and escapes due to fracturing and expulsion through the fractures [Bons \& Milligen, 2001; Kobchenko et al., 2013; Kobchenko et al., 2014; Sachau et al., 2015]. The fluctuations in the porosity and pore number density shown in Figure 3 after a temperature of $\approx 250{ }^{\circ} \mathrm{C}$ was reached may be caused by a variety of processes constrained by confinement. These include: fracture growth and fracture opening, which may connect two or more pores; fracture closing, which may create pores; fracture nucleation and growth which may create voids that are too small to be counted as fractures; and the decomposition of kerogen and thermally unstable inorganic minerals, which may create voids as the volume of solid decreases. Apparent fluctuations may also occur because void boundaries cannot be determined with sufficient accuracy and precision.

There is inevitability some ambiguity in the origin of both the pre-existing voids in the Green River Shale samples, and those formed during the experimental heating process. Voids may be the gaps between mineral grains and they may be formed by dissolution, fracturing or other processes. For example, the voids within kerogen particles may be formed by phase separation of fluids produced from the maturing kerogen, as it undergoes chemical transformation and ductile deformation. Void sizes and geometries may also be modified by compaction, mineral precipitation and deformation. These processes result in the formation of voids with a very broad distribution of shapes and sizes, and it is not always possible to deduce the origins of voids from these characteristics, particularly in two-dimensional images. Nevertheless, well-developed fractures do have characteristic shapes. They typically have a quasi-planar shape with a large ratio between the characteristic dimensions parallel to the plane of the fracture and the mean aperture width, which distinguishes them from most other voids. However, because of fluctuations about the plane of the fracture, the roughness of the fracture perimeter and inclination of the fracture plane relative to the planes of twodimensional cuts, fractures may be difficult to distinguish from other voids in two-dimensional images. Non-destructive three-dimensional time-lapse tomography enables information to be obtained about the ways in which voids are formed, and this information is useful in distinguishing fractures from other voids and distinguishing fractures that were formed during accelerated shale maturation from fractures that were present before heating began. In addition, fractures with large ratios between the "diameter" of the fracture 
and the aperture width can usually be reliably identified in three-dimensional images. As Figures 5-9 demonstrate, DIC analysis greatly increases the reliability of identifying fractures that intersect twodimensional cuts. The results obtained in this work using three-dimensional tomogram segmentation and DIC analysis indicate that essentially all the large voids were fractures. While the use of a volume threshold of 1,000 voxels to distinguish fractures from pores is arbitrary, essentially all the voids with volumes $\geq$ 1,000 could be confidently identified as fractures. However, distinguishing between small fractures and small pores is more challenging, and it is likely that many of the "pores" with volumes $<1,000$ were fractures.

A conceptual model explaining fracture initiation, propagation, closure, and reopening in the context of primary migration is illustrated in Figure 10. The key elements of the model are:

1. Fracturing is driven primarily by the production of hydrocarbon fluids, $\mathrm{CO}_{2}$ and water from kerogen, and the increase in fluid volume brought about by the cracking of high molecular mass kerogen decomposition products. However, desorption of water and the production of fluids from easily decomposed inorganic minerals may be important in some cases. The kerogen patches/flakes from which most of the fluid is generated, are distributed throughout the shale and most kerogen patches are aligned more-or-less parallel to the bedding plane, but some are oriented in other directions.

2. Because fracturing is driven by the production of fluids from kerogen, it is likely that most fractures nucleate within the kerogen or at the interface between kerogen and inorganic minerals [Allan et al., 2014] and propagate along the bedding plane. Petrography observations also showed that the main cracks initiate in the finer grained clay-rich layers where a higher amount of organic matter is present [Kobchenko et al., 2011]. Damage was observed to initiate at multiple locations within the same interface between two laminations [Panahi et al., 2012].

3. At depths where catagenesis occurs, typically $>1 \mathrm{~km}$, non-horizontal fractures are also formed preferentially along the plane perpendicular to the least principal compressive stress (perpendicular to most of the kerogen flakes), or along the plane perpendicular to the direction in which the tensile strength is smallest, which tends to be oriented along the planes of kerogen flakes. Both horizontal (bed parallel) and non-horizontal fractures are more likely to form in the unconfined experiments, such as experiment 3 , than in confined experiments. In the confined experiments, less fracturing and lower fracture porosity can be expected because the larger effective compressive stress acting on the solid matrix closes open fractures and suppresses fracture nucleation and propagation. In addition, under confined conditions, the volume of the produced fluid is smaller because of the pressure of the produced fluid is higher (the higher pressure compresses gases, increases gas sorption, increases the dissolution of gases in liquids if they are present and slightly compresses liquids). However, under 
unconfined conditions, expulsion of part of the produced fluid may reduce inflation of fractures and pores by the pressure of the fluid within them. Localized fluid production may result in tensile stress in the immediate vicinity of the fluid source, and this stress may become large enough to drive fracturing. However, the rates of fluid production were many orders of magnitude higher in the experiments than they are during catagenesis in the sub-surface, and very low permeabilities or very high capillary entry pressures are required to maintain high pressure differences across fluid-fluid interfaces or high local pressure gradients in the sub-surface. Even if the rate of fluid production is very small, and the low permeability is insufficient to prevent loss of fluid, it is possible that fluids are retained in the kerogen by sorption, and that the swelling pressure drives the nucleation and growth of fractures. In the case of kerogen flakes, the maximum tensile stress is concentrated onto the perimeters of the flakes, and since the orientation of the flakes is biased towards the plane of lamination, fracturing occurs preferentially along the plane of lamination. Strength effects also favor fracturing along the bedding plane, particularly at small scales, because strength increases with decreasing scale. Fracturing out of the bedding plane probably occurs because of kerogen flakes that are not oriented parallel to the bedding plane, and because of pores, zones of weakness (microcrevices between uncemented or weakly cemented mineral grains) and kerogen flakes with complex shapes. Small scale fracturing caused by fluid production is essentially a mode I hydraulic fracturing process and the effective stress acting on the solid matrix causes fracturing perpendicular to the direction of the least tensile strength. Earlier it was observed that the microfractures (damage zones) grow within an interface. Then damaged regions expand and finally interconnect to form a fracture that spans the entire sample [Panahi et al., 2012].

4. External confinement influences the nucleation and propagation of fractures, and also plays an important role in fracture healing. Fracture opening and closing is coupled with fluid flow within the shale and the expulsion of fluids from it. Because this is a highly nonlinear process, and because of the long-range nature of the elastic Green's function, the opening or closing of one fracture affects all the fractures within a distance that is many times the length of the fracture, though the change in stress is concentrated onto a volume on the order of $\mathrm{L}^{3}$ in in the vicinity of the fracture, where $\mathrm{L}$ is the fracture diameter. Therefore, the dynamics of fracturing and fluid expulsion is complex. Intermittency and quasi-periodicity of both fluid expulsion events and fracturing is one of the characteristics of this complexity. Complex fracture opening and closing dynamics has been reported during the deformation of a variety of brittle materials, and it is associated with strongly non-linear strain-stress relationships [Li \& Nordlund, 1993; Chorney et al., 2012; Shahid et al. 2015]. Sequential reopening of fractures (if enough fluid is driven into these weakened zones) and re-closure of inflated fractures (once the fluids flow out of them) continues until the chemical transformation of the organic 
material ceases. Cessation of kerogen maturation results in permanent closure of most of the fractures, unless they become filled with bitumen, pyrobitumen or inorganic minerals.

\section{CONCLUSION}

Heating of Green River shales in the laboratory emulates the geothermal heating of the shales during burial, but on a very much shorter time scale. The nucleation and growth of fractures was detected at much lower temperatures in these experiments than in an earlier investigation at lower spatial resolution [Kobchenko et al., 2011; Panahi et al., 2012]. The main findings of this work are:

- The growth of fractures in shales during the maturation of organic matter was imaged at spatial resolutions down to 0.56 micrometer, which was beneficial for tracking fractures at the onset of fracturing. Because fracturing is driven by the production of fluids from the kerogen, it is likely that fracture nucleation occurs within the kerogen, at the interface between kerogen and inorganic minerals or near the perimeters of kerogen flakes.

- The heating schedule directly affects the average fracture surface area, average fracture volume, fracture intensity, fracture number density, and final total generated porosity.

- Complex fracture propagation/opening and closing dynamics was observed in all experiments. This is attributed to: strong coupling between fluid production, flow and expulsion; the propagation, opening and closing of fractures; the long range nature of the elastic Green's function; and the nonlinearity of the coupled system.

- The formation of fractures that were strongly inclined relative to the bedding plane is attributed to a minority of similarly inclined kerogen flakes as well as kerogen particles that have complex shapes. Pores or zones of weakness near to kerogen flakes may also result in the formation of nonhorizontal fractures.

Acknowledgements: Elodie Boller at the European Synchrotron Radiation Facility in Grenoble, France is thanked for technical support. This study received funding from the Norwegian Research Council (project Prometheus, grant 267775) and beam time was allocated at the European Synchrotron Radiation Facility. Data storage was provided by UNINETT Sigma2 - the National Infrastructure for High Performance Computing and Data Storage in Norway (project NS9073K). Constructive reviews by the Editor and two anonymous reviewers significantly improved this paper.

\section{REFERENCES}

[1] Allan, A.M., Vanorio, T. and Dahl, J.E., 2014. Pyrolysis-induced P-wave velocity anisotropy in organic-rich shales. Geophysics, 79(2), pp.D41-D53. 
[2] Beard, T. and Van Meurs, P., Shell Oil Co, 1973. Process for solution mining nahcolite. U.S. Patent $3,779,602$.

[3] Beard, T.N., Tait, D.B. and Smith, J.W., 1974. Nahcolite and Dawsonite Resources in the Green River Formation, Guidebook to the Energy Resources of the Piceance Creek Basin, Colorado: Rocky Mountain association of geologists. pp 101-122.

[4] Bendat, J.S. and Piersol, A.G., 1986. Random Data Analysis and Measurement Techniques, $4^{\text {th }}$ Edition. J. Wiley Interscience, New York, NY, USA.

[5] Bons, P.D. and van Milligen, B.P., 2001. New experiment to model self-organized critical transport and accumulation of melt and hydrocarbons from their source rocks. Geology, 29(10), pp. 919-922.

[6] Bray, E.E. and Foster, W.R., 1980. A process for primary migration of petroleum. AAPG Bulletin, 64(1), pp. 107-114.

[7] Brown, E.T. and Hoek, E., 1978. Trends in relationships between measured in-situ stresses and depth. International Journal of Rock Mechanics and Mining Sciences \& Geomechanics Abstracts (Vol. 15, No. 4, pp. 211-215). Pergamon.

[8] Burnham, A.K. and McConaghy, J.R., 2014. Semi-open pyrolysis of oil shale from the Garden Gulch Member of the Green River Formation. Energy \& Fuels, 28(12), pp.7426-7439.

[9] Burnham, A.K., 2017. Porosity and permeability of Green River oil shale and their changes during retorting. Fuel, 203, pp.208-213.

[10] Bustin, R.M., Bustin, A.M., Cui, A., Ross, D. and Pathi, V.M., 2008. Impact of shale properties on pore structure and storage characteristics. In SPE shale gas production conference. Society of Petroleum Engineers, SPE-119892-MS, 28 pages, https://doi.org/10.2118/119892-MS

[11] Chanchani, J., Berg, R.R. and Lee, C.I., 1996. Pressure solution and microfracturing in primary oil migration, upper cretaceous Austin Chalk, Gulf Coast Association of Geological Societies Transactions, 46, pp. 71-78.

[12] Chen, J., Zhang, G., Chen, H. and Yin, X., 2014. The construction of shale rock physics effective model and prediction of rock brittleness. In SEG Technical Program Expanded Abstracts 2014 (pp. 2861-2865). Society of Exploration Geophysicists.

[13] Chenevert, M.E., 1970. Shale alteration by water adsorption. Journal of petroleum technology, 22(09). pp. 1-141.

[14] Cheng, B., Zhao, J., Yang, C., Tian, Y. and Liao, Z., 2017a. Evidences for occluded hydrocarbon transfer with geomacromolecule evolution. $28^{\text {th }}$ International Meeting for Organic Chemistry. Florence, Italy. 2 pages 

Occluded Hydrocarbons inside Geomacromolecules: A Review. Energy \& Fuels, 31(9), pp.88238832.

[16] Chorney, D., Jain, P., Grob, M. and van der Baan, M., 2012. Geomechanical modeling of rock fracturing and associated microseismicity. The Leading Edge, 31(11), pp.1348-1354.

[17] Cordell, R.J., 1973. Colloidal soap as proposed primary migration medium for hydrocarbons. AAPG Bulletin, 57(9), pp.1618-1643.

[18] Dutkiewicz, A., Volk, H., Ridley, J. and George, S.C., 2004. Geochemistry of oil in fluid inclusions in a middle Proterozoic igneous intrusion: implications for the source of hydrocarbons in crystalline rocks. Organic Geochemistry, 35(8), pp.937-957.

[19] Dutrow, B. and Norton, D., 1995. Evolution of fluid pressure and fracture propagation during contact metamorphism. Journal of Metamorphic Geology, 13(6), pp.677-686.

[20] Engelder, T. and Lacazette, A., 1990. Natural hydraulic fracturing. In Proceedings of the International Symposium on Rock Joints, 4-6 June at Loen, Norway (pp. 35-43).

[21] England, W.A., Mackenzie, A.S., Mann, D.M. and Quigley, T.M., 1987. The movement and entrapment of petroleum fluids in the subsurface. Journal of the Geological Society, 144(2), pp.327-347.

[22] English, J.M., 2012. Thermomechanical origin of regional fracture systems. AAPG bulletin, 96(9), pp.1597-1625.

[23] Ezidiegwu, S.N., 2015. Investigation of the pore size and structure in organic-rich shales (Doctoral dissertation), The University of Texas at Austin.

[24] Figueroa Pilz, F., Dowey, P.J., Fauchille, A.L., Courtois, L., Bay, B., Ma, L., Taylor, K.G., Mecklenburgh, J. and Lee, P.D., 2017. Synchrotron tomographic quantification of strain and fracture during simulated thermal maturation of anorganic-rich shale, UK Kimmeridge Clay. Journal of Geophysical Research: Solid Earth, 122, pp. 2553-2564.

[25] Glatz, G., Castanier, L.M. and Kovscek, A.R., 2016. Visualization and Quantification of Thermally Induced Porosity Alteration of Immature Source Rock Using X-ray Computed Tomography. Energy \& Fuels, 30(10), pp.8141-8149.

[26] Goulart Teixeira, M., Donzé, F., Renard, F., Panahi, H., Papachristos, E. and Scholtès, L., 2017. Microfracturing during primary migration in shales. Tectonophysics, 694, pp.268-279.

[27] Guo, J.C., Zhao, Z.H., He, S.G., Liang, H. and Liu, Y.X., 2015. A new method for shale brittleness evaluation. Environmental Earth Sciences, 73(10), pp.5855-5865.

[28] Herman, G.T., 2009. Fundamentals of computerized tomography: image reconstruction from projections. Michigan, IL. Springer Science \& Business Media. 

identification of elastic properties-a review. Strain, 42(2), pp.69-80.

[30] Hueckel, T. and Borsetto, M., 1990. Thermoplasticity of saturated soils and shales: constitutive equations. Journal of Geotechnical Engineering, 116(12), pp.1765-1777.

[31] Hunt, J.M., 1990. Generation and migration of petroleum from abnormally pressured fluid compartments (1). AAPG Bulletin, 74(1), pp.1-12.

[32] Jagniecki, E.A. and Lowenstein, T.K., 2015. Evaporites of the Green River Formation, Bridger and Piceance Creek Basins: deposition, diagenesis, paleobrine chemistry, and eocene atmospheric CO2. In Stratigraphy and Paleolimnology of the Green River Formation, Western USA (pp. 277-312). Springer Netherlands.

[33] Jin, Z.H., Johnson, S.E. and Fan, Z.Q., 2010. Subcritical propagation and coalescence of oil-filled cracks: Getting the oil out of low-permeability source rocks. Geophysical Research Letters, 37, L01305, doi:10.1029/2009GL041576.

Kalani, M., Jahren, J., Mondol, N.H. and Faleide, J.I., 2015. Petrophysical implications of source rock microfracturing. International Journal of Coal Geology, 143, pp.43-67.

[35] Kibodeaux, K.R., 2014. Evolution of porosity, permeability, and fluid saturations during thermal conversion of oil shale. SPE-170733-MS. In SPE annual technical conference and exhibition. Society of Petroleum Engineers. https://doi.org/10.2118/170733-MS

[36] Kobchenko, M., Panahi, H., Renard, F., Dysthe, D.K., Malthe-Sørenssen, A., Mazzini, A., Scheibert, J., Jamtveit, B. and Meakin, P., 2011. 4D imaging of fracturing in organic-rich shales during heating. Journal of Geophysical Research: Solid Earth, 116, B12201, doi:10.1029/2011JB008565.

[37] Kobchenko, M., Hafver, A., Dysthe, D.K. and Renard, F., 2013. Temporal evolution of a drainage fracture network into an elastic medium with internal fluid generation. In EGU General Assembly Conference Abstracts (Vol. 15, p. 12880).

[38] Kobchenko, M., Hafver, A., Jettestuen, E., Renard, F., Galland, O., Jamtveit, B., Meakin, P. and Dysthe, D.K., 2014. Evolution of a fracture network in an elastic medium with internal fluid generation and expulsion. Physical Review E, 90(5), p.052801.

[39] Lafargue, W., Espitalie, J., Broks, T.M. and Nyland, B., 1994. Experimental simulation of primary migration. Organic geochemistry, 22(3-5), pp.575-586.

[40] Lafargue, E., Marquis, F. and Pillot, D., 1998. Rock-Eval 6 applications in hydrocarbon exploration, production, and soil contamination studies. Revue de l'Institut Français du Pétrole, 53(4), pp.421-437. 

catagenesis: Example from the Catskill delta complex. AAPG Bulletin, 89(11), pp.1433-1449.

[42] Le Doan, T.V., Bostrom, N.W., Burnham, A.K., Kleinberg, R.L., Pomerantz, A.E. and Allix, P., 2013. Green River oil shale pyrolysis: Semi-open conditions. Energy \& Fuels, 27(11), pp.6447-6459.

[43] Li, C. and Nordlund, E., 1993. Deformation of brittle rocks under compression-with particular reference to microcracks. Mechanics of Materials, 15(3), pp.223-239.

[44] McAuliffe, C.D., 1979. Oil and gas migration--chemical and physical constraints. AAPG Bulletin, 63(5), pp.761-781.

[45] McGarr, A. and Gay, N.C., 1978. State of stress in the earth's crust. Annual Review of Earth and Planetary Sciences, 6(1), pp.405-436.

[46] McKay, J.F. and Chong, S.L., 1983. Characterization of organic matter recovered from Green River oil shale at temperatures of $400 \mathrm{C}$ and below. Liquid Fuels Technology, 1(4), pp.289324.

[47] Nygård, R., Gutierrez, M., Bratli, R.K. and Høeg, K., 2006. Brittle-ductile transition, shear failure and leakage in shales and mudrocks. Marine and Petroleum Geology, 23(2), pp.201-212.

[48] Ougier-Simonin, A., Renard, F., Boehm, C. and Vidal-Gilbert, S., 2016. Microfracturing and microporosity in shales. Earth-Science Reviews, 162, pp.198-226.

[49] Pan, B., Qian, K., Xie, H. and Asundi, A., 2009. Two-dimensional digital image correlation for in-plane displacement and strain measurement: a review. Measurement science and technology, 20(6), p.062001.

[50] Panahi, H., Meakin, P., Renard, F., Kobchenko, M., Scheibert, J., Mazzini, A., Jamtveit, B., Malthe-Sorenssen, A. and Dysthe, D.K., 2012. A 4D Synchrotron X-Ray-Tomography Study of the Formation of Hydrocarbon-Migration Pathways in Heated Organic-Rich Shale. SPE Journal, 18(02), pp.366-377.

[51] Peng, S. and Xiao, X., 2017. Investigation of multiphase fluid imbibition in shale through synchrotron based dynamic micro CT imaging. Journal of Geophysical Research: Solid Earth, 122(6), pp.4475-4491.

[52] Plumb, R.A., 1994, January. Variations of the least horizontal stress magnitude in sedimentary rocks. In 1st North American rock mechanics symposium. ARMA-1994-0071. American Rock Mechanics Association. 8 pages.

[53] Price, L.C., 1989. Primary petroleum migration from shales with oxygen-rich organic matter. Journal of Petroleum Geology, 12(3), pp.289-324. 

petroleum system in the Uinta basin from hydrous pyrolysis experiments. AAPG bulletin, 85(8), pp.1333-1371.

[55] Rudkiewicz, J.L., Brévart, O., Connan, J. and Montel, F., 1994. Primary migration behaviour of hydrocarbons: from laboratory experiments to geological situations through fluid flow models. Organic Geochemistry, 22(3-5), pp.631IN7-639IN8.

[56] Saif, T., Lin, Q., Singh, K., Bijeljic, B. and Blunt, M.J., 2016. Dynamic imaging of oil shale pyrolysis using synchrotron X-ray microtomography. Geophysical Research Letters, 43(13), pp.6799-6807.

[57] Saif, T., Lin, Q., Bijeljic, B. and Blunt, M.J., 2017. Microstructural imaging and characterization of oil shale before and after pyrolysis. Fuel, 197, pp.562-574.

[58] Saif, T., Lin, Q., Butcher, A.R., Bijeljic, B. and Blunt, M.J., 2017. Multi-scale multidimensional microstructure imaging of oil shale pyrolysis using X-ray micro-tomography, automated ultra-high resolution SEM, MAPS Mineralogy and FIB-SEM. Applied Energy, 202, pp.628-647.

[59] Shahid, A.S.A., Wassing, B.B., Fokker, P.A. and Verga, F., 2015. Natural-Fracture Reactivation in Shale Gas Reservoir and Resulting Microseismicity. Journal of Canadian Petroleum Technology, 54(06), pp.450-459.

[60] Snarskiy, A.N., 1961. Relationship between primary migration and compaction of rocks, Petroleum Geology: A digest of Russian literature on Petroleum Geology, 5, pp. 362-365.

[61] Savage, W.Z., Swolfs, H.S. and Amadei, B., 1992. On the state of stress in the near-surface of the Earth's crust. Pure and Applied Geophysics, 138(2), pp.207-228.

[62] Simoneit, B.R., 1988. Petroleum generation in submarine hydrothermal systems; an update. The Canadian Mineralogist, 26(3), pp.827-840.

[63] Smith, J.W. and Milton, C., 1966. Dawsonite in the Green River formation of Colorado. Economic geology, 61(6), pp.1029-1042.

[64] Thomas, G.W., 1966. Some effects of overburden pressure on oil shale during underground retorting. Society of Petroleum Engineers Journal, 6(01), pp.1-8.

[65] Timoshenko, S., Timoshenko, S.P., Timoshenko, S.P. and Timoshenko, S.P., 1956. Strength of materials (Vol. 210). New York: van Nostrand.

[66] Tissot, B.P. and Welte, D.H., 1978. Petroleum formation and occurrence. Springer-Verlag, New York, p. 538.

[67] Vernik, L., 1994. Hydrocarbon-generation-induced microcracking of source rocks. Geophysics, 59(4), pp.555-563. 
[68] White, L.B. and Boashash, B., 1990. Cross spectral analysis of nonstationary processes. IEEE Transactions on Information Theory, 36(4), pp.830-835.

[69] Zang, A. and Stephansson, O., 2009. Stress field of the Earth's crust. Springer Science \& Business Media.

[70] Zhu, D., Jin, Z., Hu, W., Song, Y. and Gao, X., 2007. Effect of igneous activity on hydrocarbon source rocks in Jiyang sub-basin, eastern China. Journal of Petroleum Science and Engineering, 59(3-4), pp.309-320. 
Tables and figures

Table 1: Experiment specifications and experimental conditions

\begin{tabular}{|c|c|c|c|c|}
\hline & $\begin{array}{l}\text { Sample/Confinement } \\
\text { internal diameter (ID) } \\
\text { and outside diameter (OD) }\end{array}$ & Sample OD & Voxel size & Heating ramp and duration \\
\hline 1 & Green River Shale/unconfined & $7 \mathrm{~mm}$ & $2.8 \mu \mathrm{m}$ & $\begin{array}{l}\text { Rapid linear temperature } \\
\text { ramp-up in } 10 \mathrm{~min} \text {. to } \\
390^{\circ} \mathrm{C} \text { and constant } \\
\text { temperature for the rest of } \\
\text { the experiment ( } 78 \mathrm{~min} .)- \\
\text { total duration of } 88 \mathrm{~min} .\end{array}$ \\
\hline 2 & Green River Shale/unconfined & $7 \mathrm{~mm}$ & $\begin{array}{l}0.56 \mu \mathrm{m} \text { and } 2.8 \\
\mu \mathrm{m}\end{array}$ & $\begin{array}{l}\text { Rapid linear temperature } \\
\text { ramp-up in } 10 \mathrm{~min} . \text { to } \\
335^{\circ} \mathrm{C} \text { and constant } \\
\text { temperature for the rest of } \\
\text { the experiment ( } 110 \mathrm{~min} \text {.) } \\
\text {-total duration of } 120 \mathrm{~min} .\end{array}$ \\
\hline 3 & Green River Shale/unconfined & $7 \mathrm{~mm}$ & $\begin{array}{l}0.56 \mu \mathrm{m} \text { and } 2.8 \\
\mu \mathrm{m}\end{array}$ & $\begin{array}{l}\text { Rapid linear temperature } \\
\text { ramp-up in } 10 \text { min. to } \\
290^{\circ} \mathrm{C} \text { and constant } \\
\text { temperature for the rest of } \\
\text { the experiment ( } 101 \mathrm{~min} \text {.) } \\
\text { - total duration of } 111 \\
\text { min. }\end{array}$ \\
\hline 4 & $\begin{array}{l}\text { Green River Shale/confined } \\
\text { with non-porous ceramic }(2 \times 4 \\
\mathrm{mm})\end{array}$ & $2 \mathrm{~mm}$ & $0.7 \mu \mathrm{m}$ & $\begin{array}{l}\text { Quasi-linear temperature } \\
\text { ramp-up to } 750^{\circ} \mathrm{C} \text { over } 8.7 \\
\text { hours }\end{array}$ \\
\hline
\end{tabular}


Table 2: Fracture statistics

\begin{tabular}{|c|c|c|c|c|c|c|c|c|c|}
\hline Experiment & $\begin{array}{l}\text { Temperat } \\
\text { ure }\end{array}$ & $\begin{array}{l}\text { Size } \\
\text { of the } \\
\text { 3D } \\
\text { volu } \\
\text { me }\end{array}$ & $\begin{array}{l}\text { Void } \\
\text { graysc } \\
\text { ale } \\
\text { intensit } \\
\text { y }\end{array}$ & $\begin{array}{l}\text { Fractu } \\
\text { re } \\
\text { count } \\
(\geq 1,0 \\
00 \\
\text { voxel) }\end{array}$ & $\begin{array}{l}\text { Avera } \\
\text { ge } \\
\text { fractu } \\
\text { re } \\
\text { surfac } \\
\text { e area } \\
\text { (pixel }{ }^{2} \\
\text { ) }\end{array}$ & $\begin{array}{l}\text { Avera } \\
\text { ge } \\
\text { fractu } \\
\text { re } \\
\text { volum } \\
\text { e } \\
\text { (voxel } \\
\text { ) }\end{array}$ & $\begin{array}{l}\text { Fractu } \\
\text { re } \\
\text { numb } \\
\text { er } \\
\text { densit } \\
\text { y }\end{array}$ & $\begin{array}{l}\text { Fractu } \\
\text { re } \\
\text { intensi } \\
\text { ty }\end{array}$ & $\begin{array}{l}\text { Fracture } \\
\text { porosity, } \\
\%\end{array}$ \\
\hline $\begin{array}{l}\text { Experiment 1, } \\
\text { scan } 2 \\
\text { (15.6-31.2 min.) }\end{array}$ & $390^{\circ} \mathrm{C}$ & $\begin{array}{l}3.85 \\
\times 10^{-7} \\
\mathrm{~m}^{3}\end{array}$ & $\begin{array}{l}100- \\
255\end{array}$ & 29 & $\begin{array}{l}39,59 \\
0\end{array}$ & $\begin{array}{l}45,43 \\
3\end{array}$ & $\begin{array}{l}7.53 \\
\times 10^{7} / \\
\mathrm{m}^{3} \text { rock } \\
\text { mass }\end{array}$ & $\begin{array}{l}1.39 / \\
\mathrm{m}_{\text {rock }} \\
\text { mass }\end{array}$ & \\
\hline $\begin{array}{l}\text { Experiment } 1 \text {, } \\
\text { scan } 5 \\
\text { (62.8-78 } \mathrm{min} .)\end{array}$ & $390^{\circ} \mathrm{C}$ & $\begin{array}{l}3.85 \\
\times 10^{-7} \\
\mathrm{~m}^{3}\end{array}$ & $\begin{array}{l}100- \\
255\end{array}$ & 27 & 234 & 274 & $\begin{array}{l}7.01 \\
\times 10^{7} / \\
\mathrm{m}^{3} \text { rock } \\
\text { mass }\end{array}$ & $\begin{array}{l}8.24 \\
\times 10^{-3} / \\
\mathrm{m}_{\text {rock }} \\
\text { mass }\end{array}$ & 0.9 \\
\hline Experiment 2 & $335^{\circ} \mathrm{C}$ & $\begin{array}{l}3.85 \\
\times 10^{-7} \\
\mathrm{~m}^{3}\end{array}$ & $\begin{array}{l}110- \\
255\end{array}$ & 2,800 & 72 & 65 & $\begin{array}{l}7.3 \\
\times 10^{9} / \\
\mathrm{m}^{3} \text { rock } \\
\text { mass }\end{array}$ & $\begin{array}{l}2.53 \\
\times 10^{-3} / \\
\mathrm{m}_{\text {rock }} \\
\text { mass }\end{array}$ & 0.73 \\
\hline Experiment 3 & $290^{\circ} \mathrm{C}$ & $\begin{array}{l}3.85 \\
\times 10^{-7} \\
\mathrm{~m}^{3}\end{array}$ & $\begin{array}{l}110- \\
255\end{array}$ & 895 & 31 & 20 & $\begin{array}{l}2.3 \\
\times 10^{9} / \\
\mathrm{m}^{3} \text { rock } \\
\text { mass }\end{array}$ & $\begin{array}{l}1.09 \\
\times 10^{-3} / \\
\mathrm{m}_{\text {rock }} \\
\text { mass }\end{array}$ & 0.55 \\
\hline
\end{tabular}




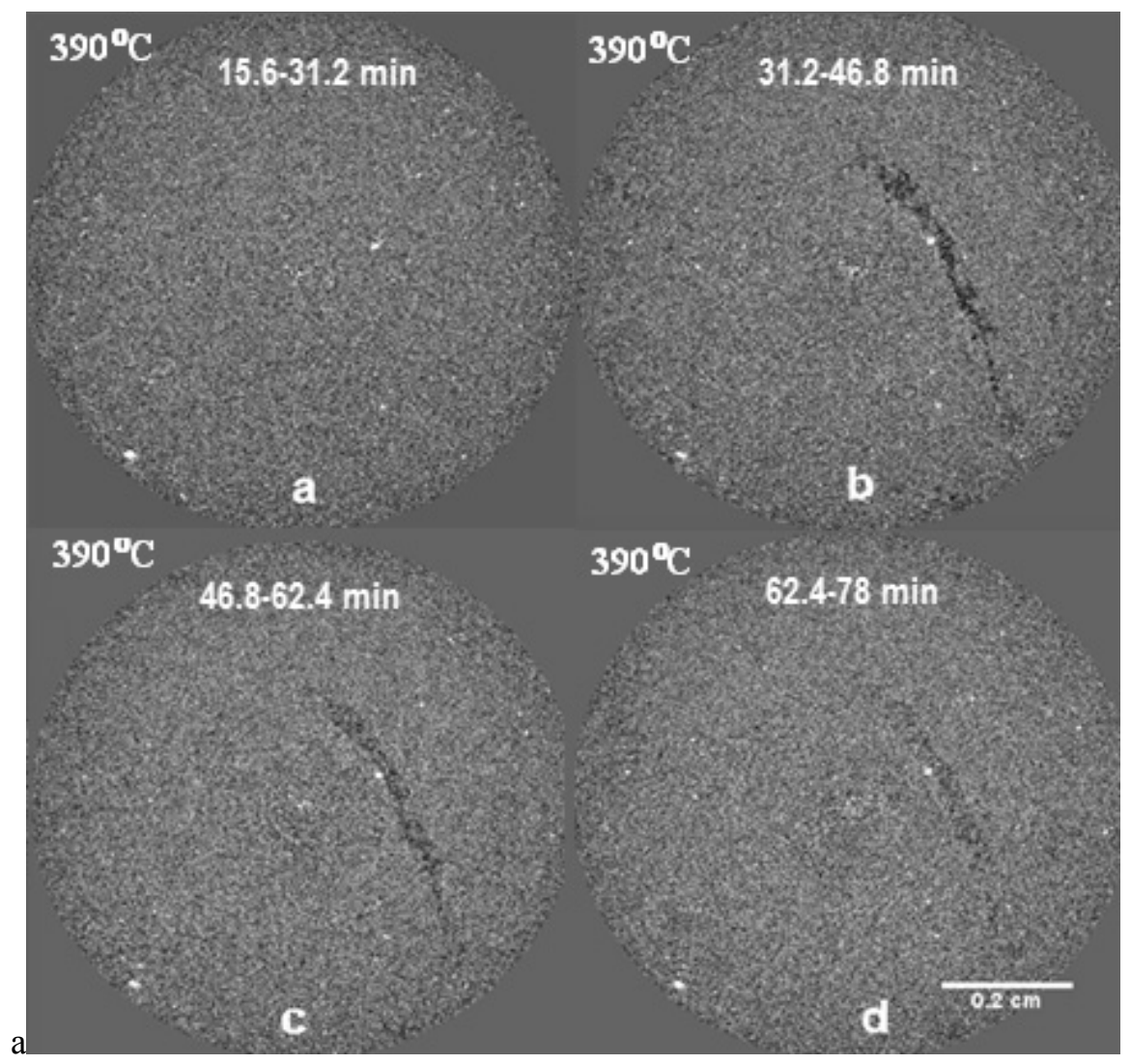

Figure 1: Fracture evolution in experiment 1 (unconfined). a) Near the beginning of the experiment (15.6 to 31.2 minutes after a constant temperature of $390^{\circ} \mathrm{C}$ was reached) no fractures could be observed; b) After 31.2 to 46.8 minutes at $390^{\circ} \mathrm{C}$, a diagonal fracture formed in the chosen bed-parallel $2 \mathrm{D}$ slice; the fracture appearing as a band of dark connected voxels; c-d) The fracture started to close as the produced gas was expelled from the fracture down a fluid pressure gradient. The process was observed in three dimensions and the 2D images are only for illustration purposes. 

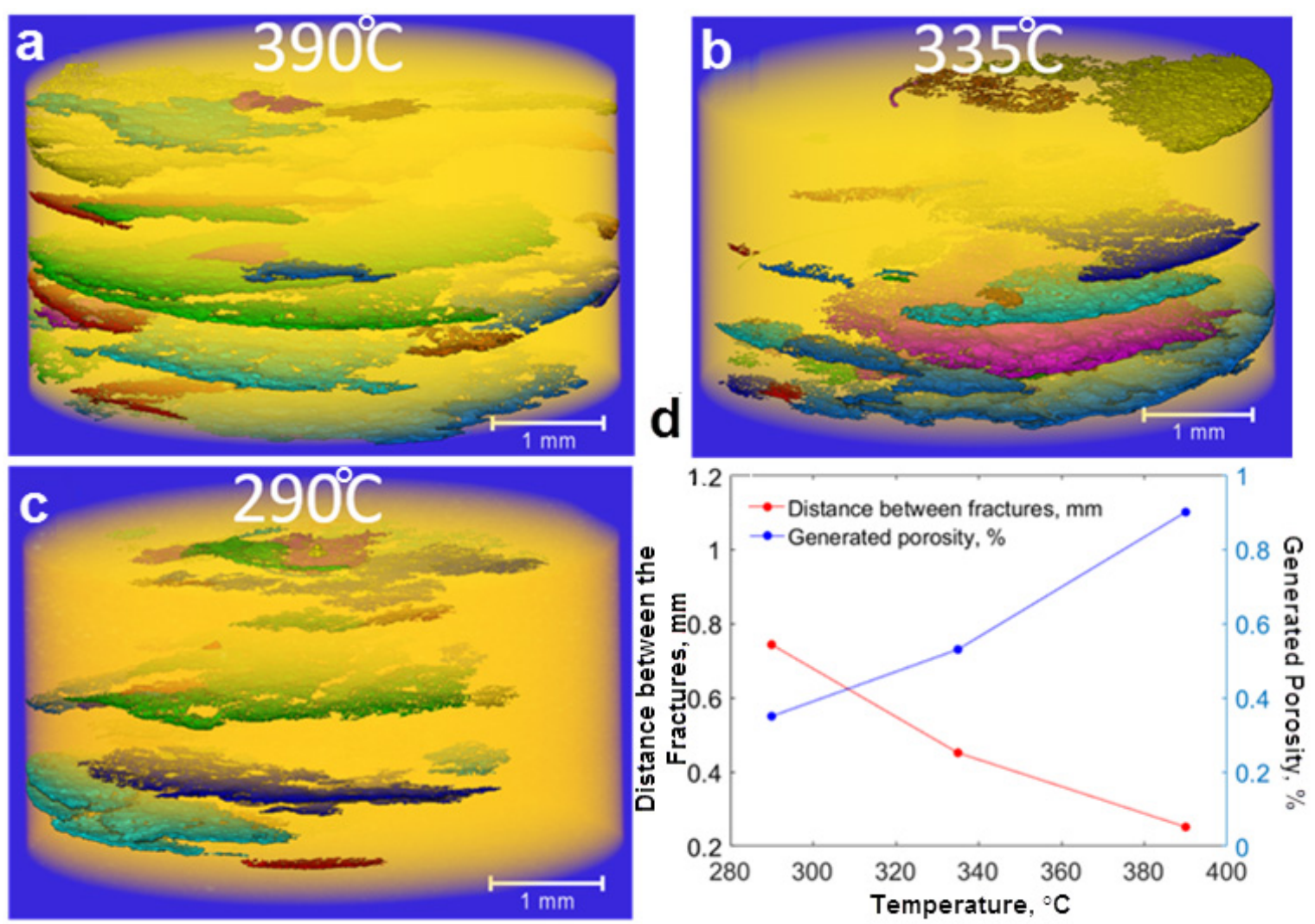

Figure 2: The spatial distribution of the fractures formed during hydrocarbon generation at three temperatures (Experiments 1, 2 and 3), without confinement. Fractures that are not connected in 3D space are indicated by different colors. a) Fracture network at the end of experiment 1 , after heating at $390^{\circ} \mathrm{C}, \mathrm{b}$ ) Fracture network at the end of experiment 2, after heating at $335^{\circ} \mathrm{C}$, c) Fracture network at the end of experiment 3 after heating at $290^{\circ} \mathrm{C}$. d) Generated fracture porosity in experiments 1,2 and 3 . The average distance between fractures is defined as the average of the distances along each vertical column of voxels that spans the gap between one fracture and another without intersecting another fracture. At higher temperatures more fractures were generated resulting in larger fracture porosities. 

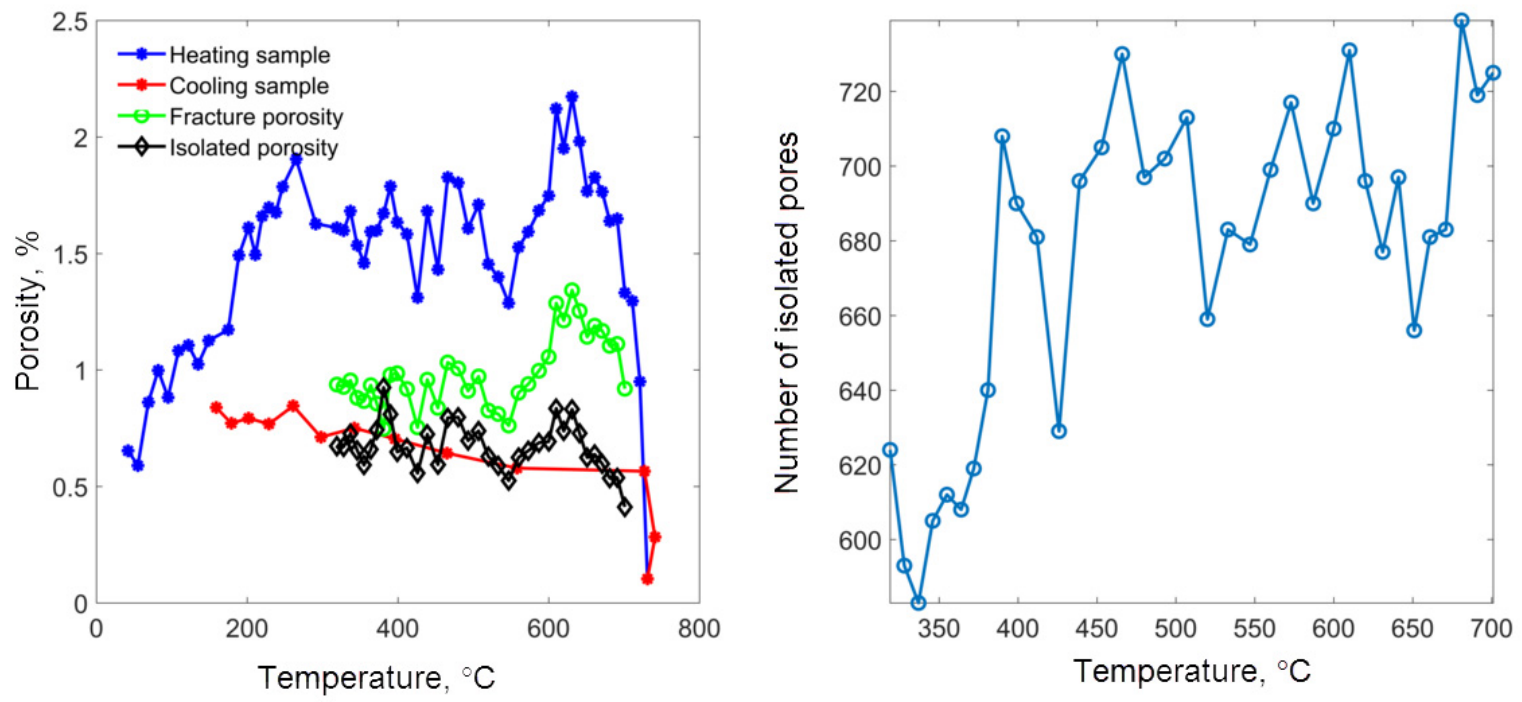

Figure 3: a) Evolution of the XCT porosity under confined conditions during experiment 4 as the temperature was increased. The total porosity is shown in blue, the contribution of the fractures (fracture porosity) is shown in green and the contribution of the other pores, which are randomly distributed in the sample, is shown in black. The decrease in total porosity during cooling is shown in red. b) The variation with temperature of the number of isolated pores as the temperature was increased. 
a

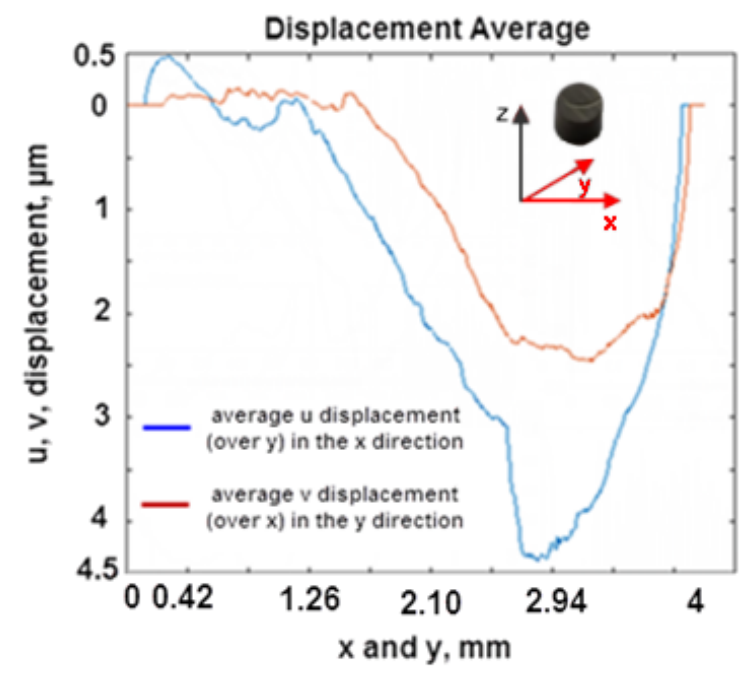

b

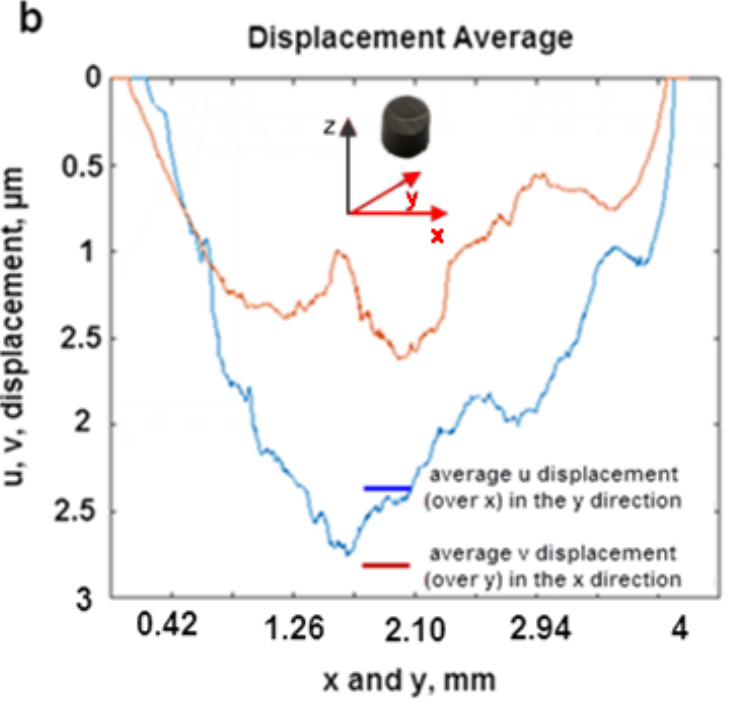

Figure 4: a) The dependence of the $y$-direction average of the $u$ displacement in the $x$ direction (blue) and the $\mathrm{x}$-direction average of the $\mathrm{v}$ displacement in the $\mathrm{y}$ direction (red) within the bedding plane between 308 ${ }^{\circ} \mathrm{C}$ and $319{ }^{\circ} \mathrm{C}$ for experiment 4 (confined, middle stages). b) The dependence of the $\mathrm{x}$-axis average of the $\mathrm{u}$ displacement in the $\mathrm{y}$ direction (blue) and the $\mathrm{y}$-axis average of the $\mathrm{v}$ displacement in the $\mathrm{x}$ direction (red). 

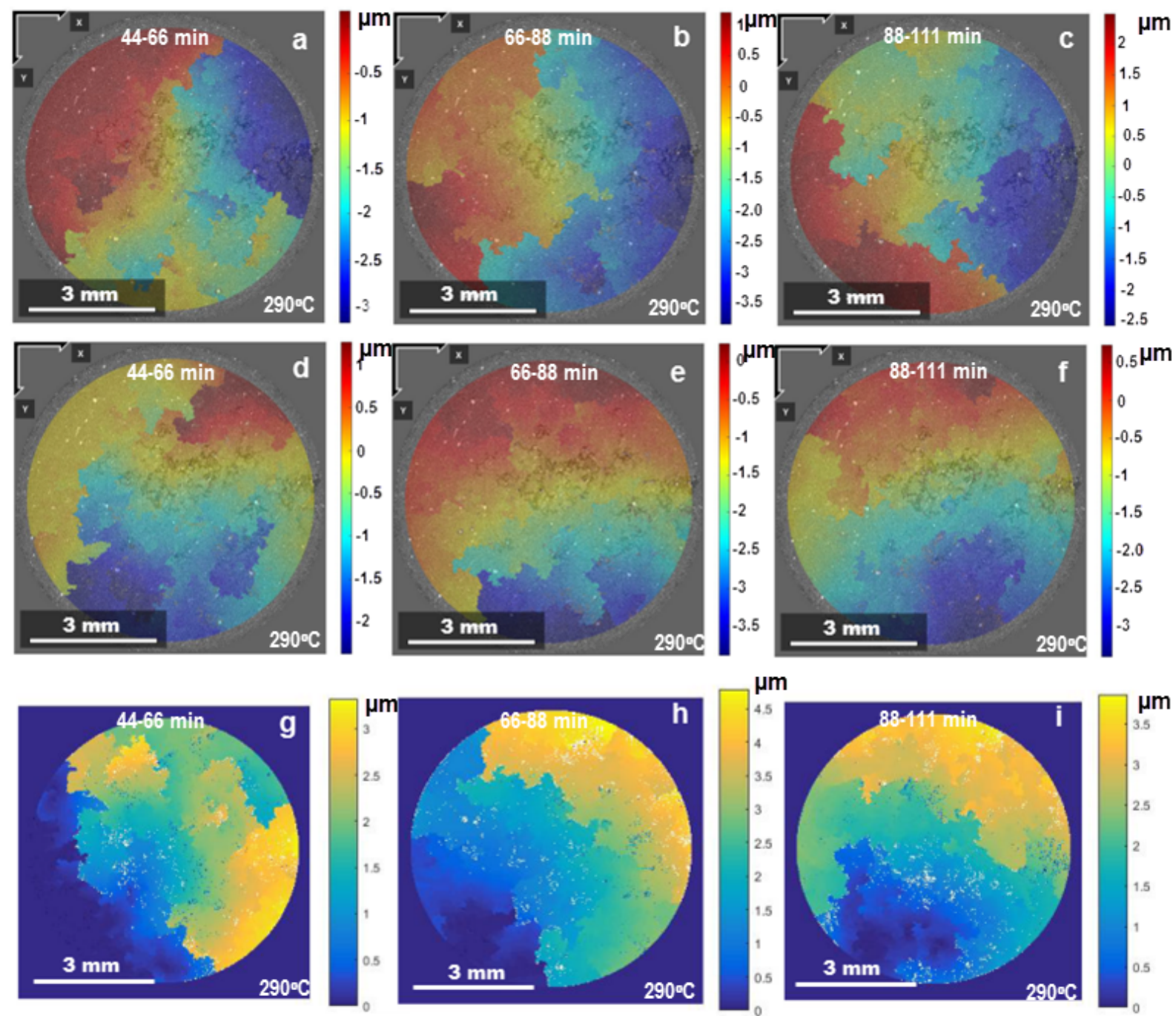

Figure 5: Lagrangian displacement fields $\mathrm{u}(\mathrm{x}, \mathrm{y})$ along the $\mathrm{x}$-axis $(\mathrm{a}-\mathrm{c}), \mathrm{v}(\mathrm{x}, \mathrm{y})$ along the $\mathrm{y}$-axis $(\mathrm{d}-\mathrm{f})$, and the total displacement ( $\mathrm{g}-\mathrm{i})$ for a bedding plane-parallel slice in experiment 3 at three different times at a constant temperature of $290^{\circ} \mathrm{C}$ with respect to the reference image, which was the $1^{\text {st }}$ image acquired after temperature stabilization. Positive displacements are indicated in warm colors and negative displacement in cold colors. The discontinuities in the color (displacement) indicate where fractures intersect the slice. 

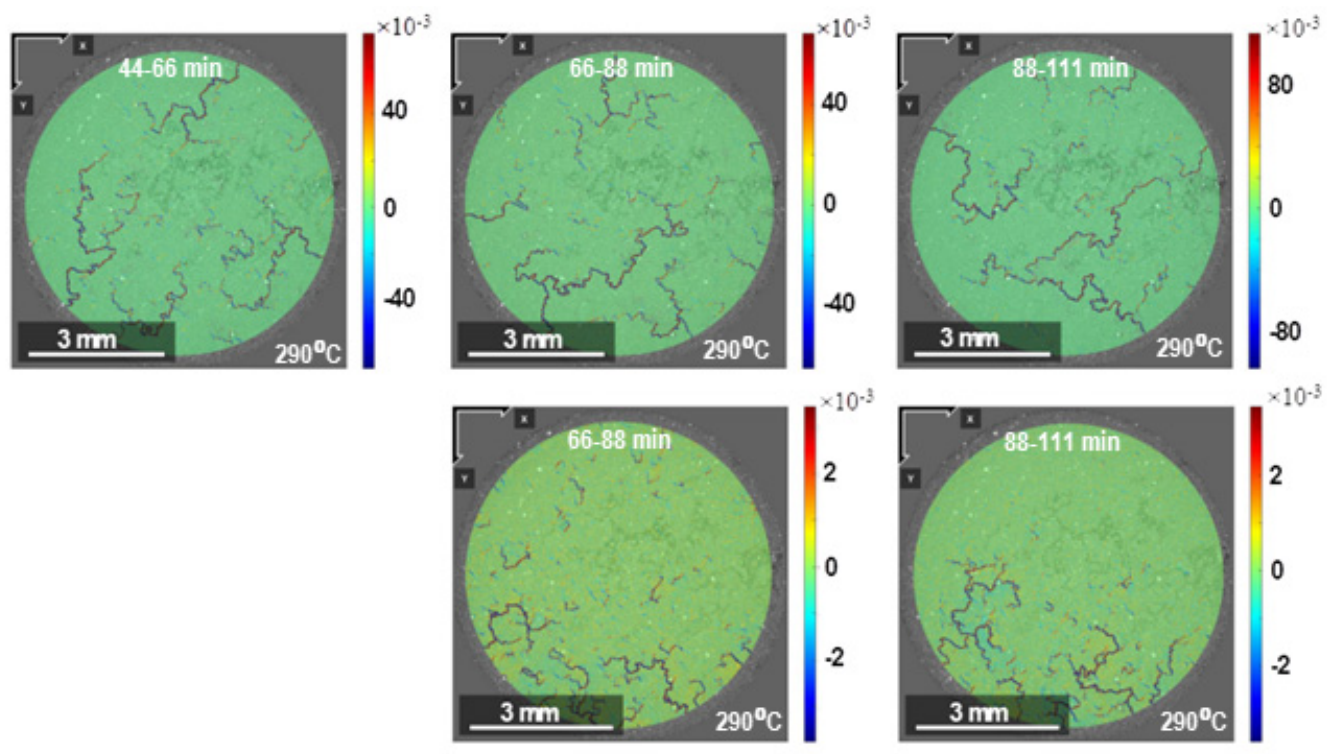

Figure 6: Lagrangian shear strain field, $E_{x y}$, corresponding to Figure 5 (experiment 3, unconfined): The first row shows the strain field calculated from the displacement field by digital image correlation (DIC) analysis with respect to the reference image (first image after the constant temperature of $290^{\circ} \mathrm{C}$ had been reached) and the second row shows the strain field calculated from the displacement field by DIC analysis with respect to the preceding image instead of the first image. Strain fronts in the first row represent the cumulative strain field development relative to the reference image while the second row strain fronts show stepwise strain field development. 


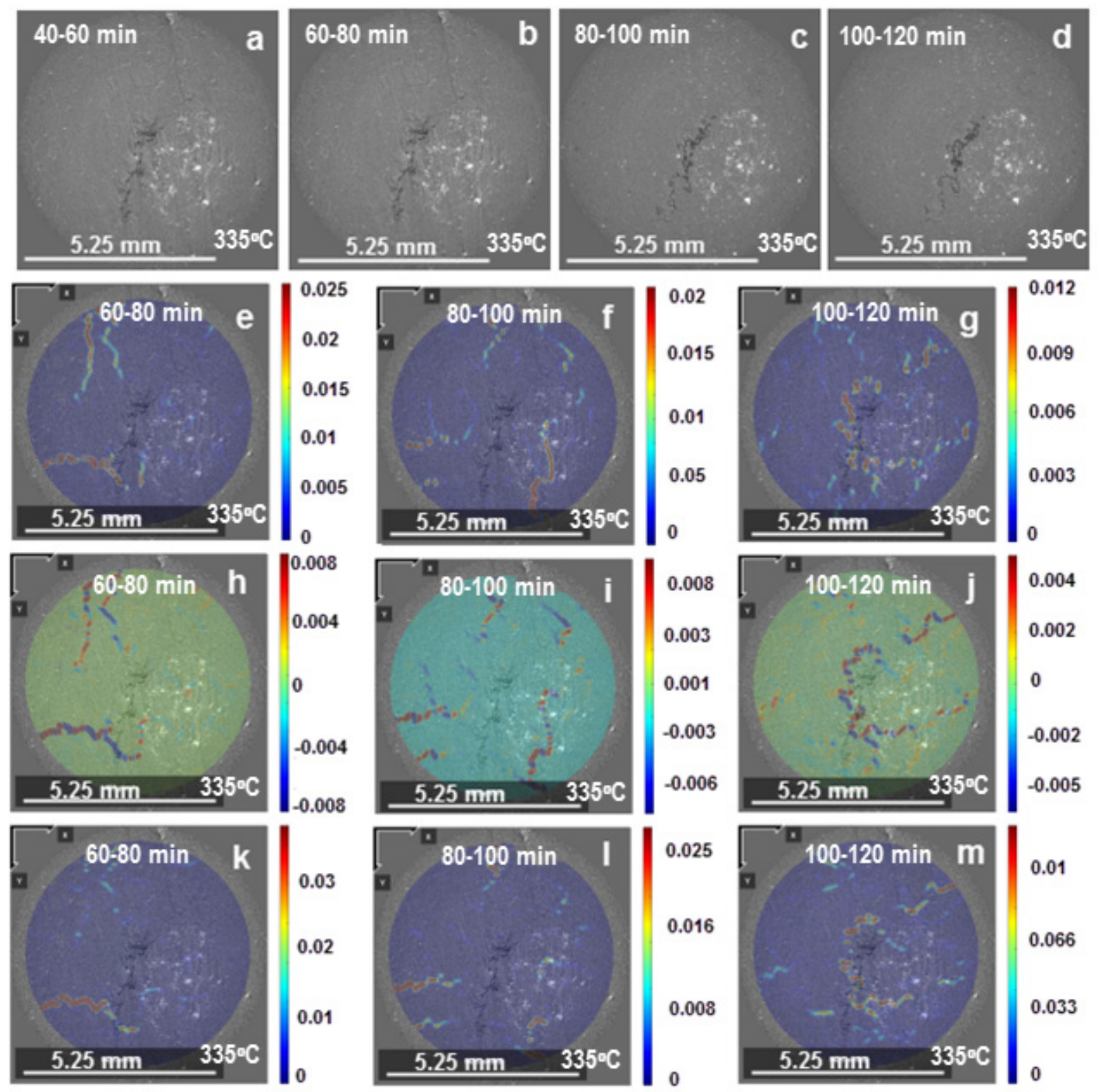

Figure 7: a-d) Heating induced evolution of the void space in a slice (along the bedding plane) of experiment 2 ( $335^{\circ} \mathrm{C}$, unconfined). e-m) Strain field components: e-h, $E_{x x} ; h-j, E_{x y}$; and k-m, $E_{y y}$. The dark pixels correspond to fractures that were present at the beginning of the analysis (immediately after a temperature of $335^{\circ} \mathrm{C}$ had been reached), which did not develop further during the heating, while the colored fronts are those that were active during the heating process. 

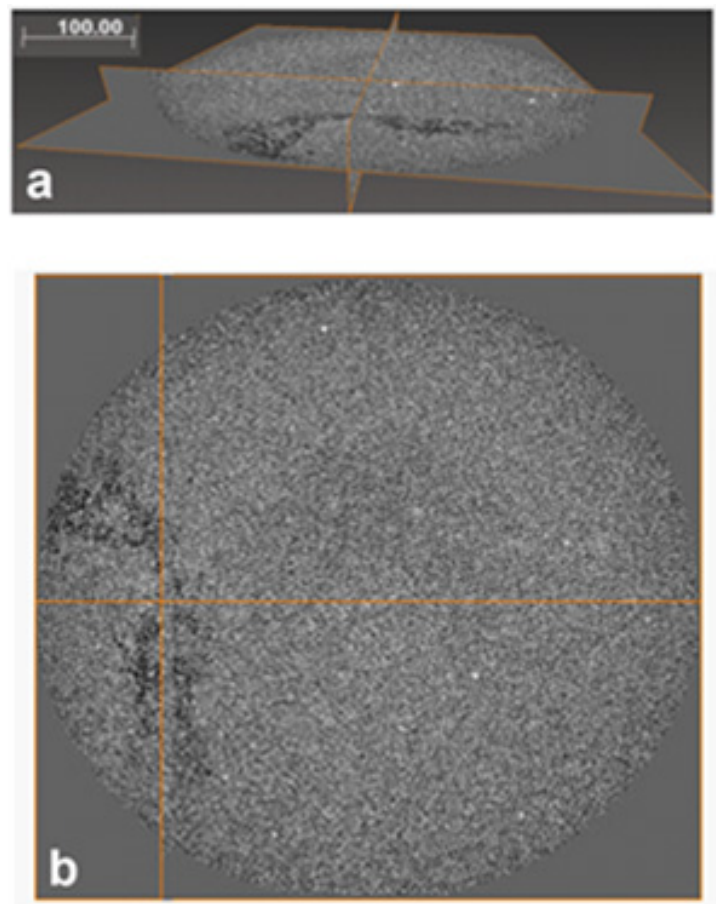

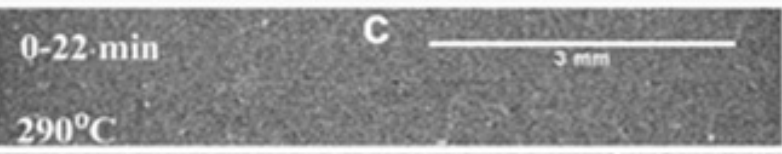

$22-44 \mathrm{~min}$
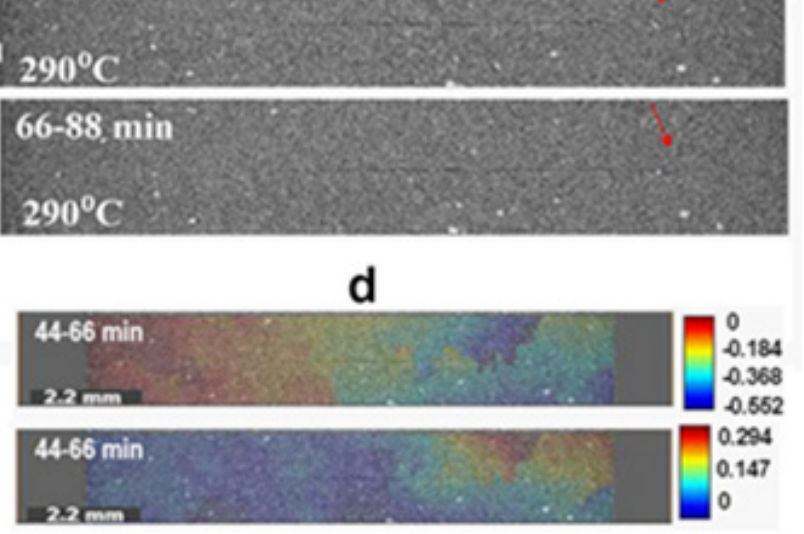

Figure 8: $\mathrm{a}$ and b) Two orthogonal bedding-plane perpendicular vertical cross sections (cross sections 1 and 2 in the text) used for DIC analysis of the deformation of the unconfined shale in experiment 3. c) Evolution of the fractures ( 3 stages) in the $x-z$ plane as the sample is heated (for cross-section 1). There are many diagonal, non-horizontal or spatially complex fractures which are not easily seen. The red arrows point at some of them. d) Horizontal, u, displacements (top) and vertical, w, displacement (bottom) for one of the cross sections after the first stage of heating. There is a significant correlation between the $u$ and $w$ displacements. In parts $\mathrm{c}$ and $\mathrm{d}$, the $\mathrm{z}$ axis is perpendicular to the bedding plane and is parallel to the axis of the cylindrical sample. 

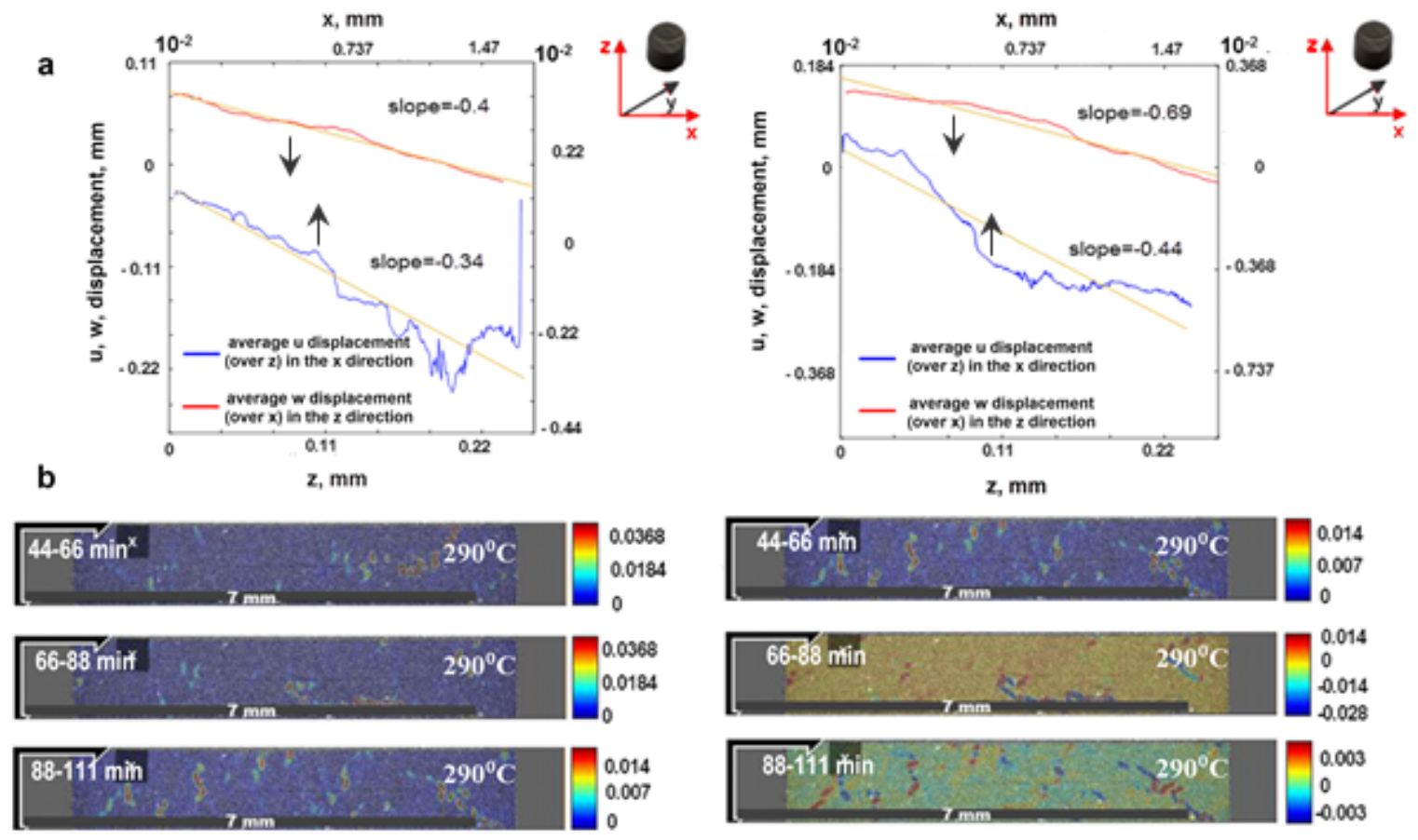

Figure 9: a) Comparison of $\mathrm{u}$ displacement averaged over $\mathrm{z}$ in the $\mathrm{x}$ direction and $\mathrm{w}$ displacement averaged over $\mathrm{x}$ in the $\mathrm{z}$ direction for orthogonal vertical cross-sections 1 and 2 of Figure 8 for experiment 3 (unconfined, $290^{\circ} \mathrm{C}$ ). a) The average $\mathrm{u}$ displacement over $\mathrm{z}$ in the $\mathrm{x}$ direction in shown in blue and average $\mathrm{w}$ displacement over $\mathrm{x}$ in the $\mathrm{z}$ direction in red. They indicate an anisotropic displacement field. $\mathrm{b}$ ) Strain tensor component Exx (left) and Exz (right) as the sample was held at the final temperature of $290^{\circ} \mathrm{C}$ for cross section 2. 

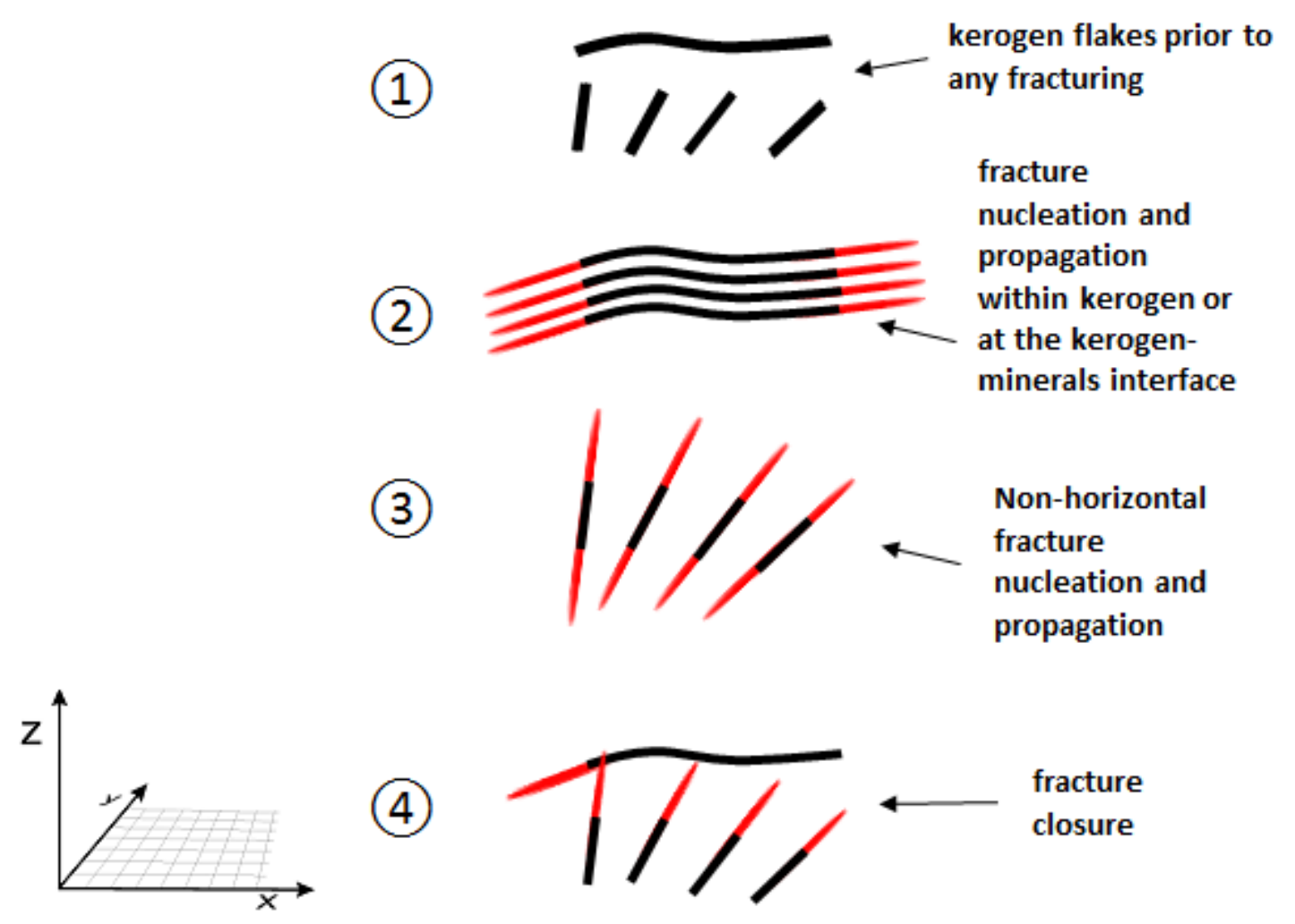

(3)

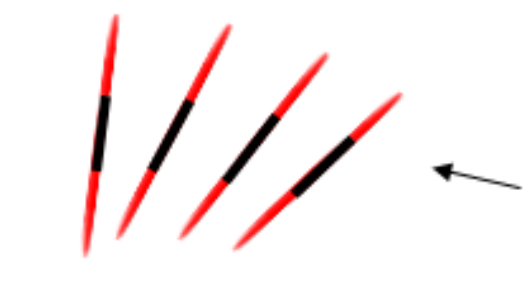

Non-horizontal
fracture
nucleation and
propagation

(4)

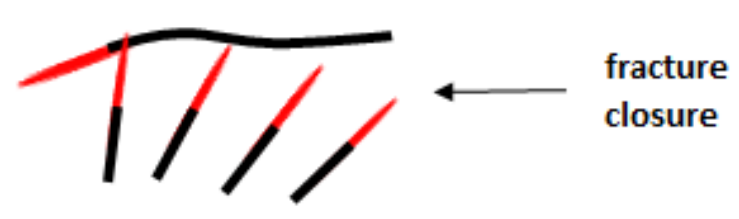

Figure 10: Conceptual model for fracture initiation, propagation, closure and reopening in the context of primary migration. The kerogen flakes are shown in black and the fractures in red. 1) The organic material, in the form of kerogen patches/flakes, is distributed throughout the shale. Most kerogen patches are aligned more-or-less parallel to the bedding plane, and a few are oriented in other directions. 2) Because fracturing is driven by the production of fluids from the kerogen, it is likely that fracture nucleation occurs within the kerogen or at the interface between kerogen and inorganic minerals. 3) Some fractures that are strongly inclined relative to the bedding plane are formed from kerogen patches that are also strongly inclined relative to the bedding plane, and because of the heterogeneous stress and strength fields. These fractures also act as conduits for produced hydrocarbon flow. 4) External fracture confinement influences the nucleation and propagation of fractures, and also plays an important role in fracture healing. 